\title{
D-Serine Augments NMDA-NR2B Receptor-Dependent Hippocampal Long-Term Depression and Spatial Reversal Learning
}

\author{
Steven Duffy*, 1,4, Viviane Labrie ${ }^{1,2,4}$ and John C Roder ${ }^{1,2,3}$ \\ 'Samuel Lunenfeld Research Institute, Mount Sinai Hospital, Toronto, ON, Canada; ${ }^{2}$ Institute for Medical Science, University of Toronto, \\ Toronto, ON, Canada; ${ }^{3}$ Departmant of Physiology, Faculty of Medicine, University of Toronto, Toronto, ON, Canada
}

\begin{abstract}
The contributions of hippocampal long-term depression (LTD) to explicit learning and memory are poorly understood. Electrophysiological and behavioral studies examined the effects of modulating NMDA receptor-dependent LTD on spatial learning in the Morris water maze (MWM). The NMDA receptor co-agonist D-serine substantially enhanced NR2B-dependent LTD, but not long-term potentiation (LTP) or depotentiation, in hippocampal slices from adult wild type mice. Exogenous D-serine did not alter MWM acquisition, but substantially enhanced subsequent reversal learning of a novel target location and performance in a delayed-matchingto-place task. Conversely, an NR2B antagonist disrupted reversal learning and promoted perseveration. Endogenous synaptic D-serine likely saturates during LTP induction because exogenous D-serine rescued deficient LTP and MWM acquisition in Grin I ${ }^{\text {48 }}$ IN mutant mice having a lower D-serine affinity. Thus, D-serine may enhance a form of hippocampal NR2B-dependent LTD that contributes to spatial reversal learning. By enhancing this form of synaptic plasticity, D-serine could improve cognitive flexibility in psychiatric disorders characterized by perseveration of aberrant ideation or behaviors.

Neuropsychopharmacology (2008) 33, I004-10 I8; doi:I 0. I038/sj.npp. I 30 I486; published online II July 2007
\end{abstract}

Keywords: long-term depression; spatial reversal learning; NR2B receptor; Morris water maze; long-term potentiation; hippocampus

\section{INTRODUCTION}

In the hippocampus, activation of postsynaptic NMDA-type glutamate receptors by high-frequency stimulation triggers long-term potentiation (LTP) of glutamatergic neurotransmission, a form of synaptic plasticity thought to underlie some forms of explicit learning (O'Keefe, 1993; Martin et al, 2000; Lynch, 2004). In contrast, low-frequency stimulation can induce an NMDA-dependent long-term synaptic depression (LTD) (Dudek and Bear, 1992; Wagner and Alger, 1996; Kemp and Bashir, 2001). Behavioral experience can dynamically modulate the induction threshold for hippocampal LTD (Manahan-Vaughan and Braunewell, 1999; Kemp and Manahan-Vaughan, 2004) but, unlike LTP, the behavioral correlates of LTD modulation have not been extensively investigated.

The NMDA receptors that mediate most lasting forms of hippocampal plasticity are heteromeric protein complexes of different subunits (NR1 $\left.1_{a-h}, N R 2 A-D, N R 3\right)$ that confer

*Correspondence: Dr S Duffy, Samuel Lunenfeld Research Institute, Mount Sinai Hospital, 600 University Avenue, Toronto, ON, Canada M5G IX5, Tel: + 416586 4800, ext. 8543, Fax: + 4165868588 ,

E-mail: duffy@mshri.on.ca

${ }^{4}$ These authors contributed equally to this work.

Received 28 December 2006; revised 17 May 2007; accepted I8 May 2007 distinct biophysical properties (Monyer et al, 1994), and show specific patterns of expression during development and across the mature mammalian CNS (Dumas, 2005). In the mature hippocampus, functional receptors consist of two NR1 subunits associated with either two NR2A subunits, two NR2B subunits, or possibly one of each (Cull-Candy et al, 2001; Loftis and Janowsky, 2003). There is evidence to suggest that receptors with different NR2 subtypes mediate distinct forms of synaptic plasticity. Antagonists to NR2B-containing NMDA receptors were found to suppress specifically LTD in hippocampus (Liu et al, 2004) and cortex (Massey et al, 2004). More recent studies, however, have found both NR2B-independent LTD (Bartlett et al, 2007; Morishita et al, 2006) and NR2Bdependent LTP (Zhao et al, 2005; Bartlett et al, 2007; Fox et al, 2006). Also, NR2B antagonists have shown inconsistent and perplexing effects on hippocampus-dependent behaviors, inhibiting cued and contextual fear conditioning (Rodrigues et al, 2001) but not spatial learning (Guscott et al, 2003; Higgins et al, 2003).

The activation of NMDA receptors requires, in addition to concurrent binding of glutamate to NR2 and membrane depolarization, binding of glycine or D-serine to the 'glycine site' of NR1 (Johnson and Ascher, 1987; Clements and Westbrook, 2001). Increasing D-serine catabolism with D-amino acid oxidase (DAO) (Hayashi et al, 1997; Wake et al, 
2001) suppresses NMDA currents and blocks hippocampal LTP (Yang et al, 2003), suggesting that D-serine is the principal endogenous co-agonist in the hippocampus and could dynamically regulate LTP and LTD.

To examine further the role of LTD in spatial learning and memory, we identified a pharmacological method for specifically modulating the magnitude of NR2B-mediated LTD in adult mouse hippocampus. Performance in several spatial learning tasks was then assessed under conditions of both NR2B-dependent LTD enhancement and pharmacological blockade. We also employed the Grin $1^{\text {D481N/D481N }}$ mutant mouse line (Kew et al, 2000) to examine the effects of exogenous D-serine on LTP and spatial learning under conditions of normal and limiting endogenous D-serine.

\section{MATERIALS AND METHODS}

\section{Experimental Animals}

Mice were housed, handled, and killed in accordance with institution and national guidelines for animal welfare (Province of Ontario Animals for Research Act, 1971 and the Canadian Council on Animal Care). C57BL/6J mice were purchased from JAX Research Systems (Bar Harbor, ME) or bred from JAX mice. Mice were housed in separately ventilated, filtered polycarbonate cages, 3-5 mice per cage, with sterile water, and rodent chow ad libitum. The animal colony is temperature $\left(20 \pm 1{ }^{\circ} \mathrm{C}\right)$ and humidity (50-60\%) controlled, with a $12 \mathrm{~h}$ diurnal cycle (lights on from 0700 to $1900 \mathrm{~h})$. Mice expressing the Grin $1^{\text {D481N/D481N }}$ mutation were derived from founders generously provided by $\mathrm{Dr}$ M Pauley-Evers, Hoffmann-La Roche Ltd. (Basel, Switzerland). The D481N mutation was confirmed in our Grin1 stock by sequencing the $450 \mathrm{bp}$ fragment using an ABI PRISM 377 DNA Sequencer (Applied Biosystems Inc., Foster City, CA). These animals were backcrossed to the C57BL/6J strain for 11 generations before experiments. All animals used for behavioral testing and electrophysiology were 4-6 months of age. Mice that were tested in behavioral tests were not used for electrophysiological experiments. The Grin $1^{\text {D481N/D481N }}$ mutation (aspartate to asparagine substitution at amino acid 481) is in the NR1 glycine-binding region and confers an approximately fivefold lower co-agonist affinity in the homozygous state (Kew et al, 2000).

To genotype the Grin1 line, tail clippings $(0.5-1.0 \mathrm{~cm})$ were taken and digested overnight in $600 \mathrm{ml}$ TNES buffer (10 mM Tris- $\mathrm{HCl}, 400 \mathrm{mM} \mathrm{NaCl}, 100 \mathrm{mM}$ EDTA, 0.6\% SDS, $\mathrm{pH}$ 7.5) and $20 \mu \mathrm{l}$ Proteinase $\mathrm{K}$ (Roche Diagnostics Canada, Laval, PQ). Genomic DNA was isolated by the addition of $170 \mu \mathrm{l} 6.0 \mathrm{M}$ sodium chloride, followed by ethanol precipitation and centrifugation. DNA was then dissolved in $20 \mathrm{mM}$ Tris- $\mathrm{HCl}, \mathrm{pH}$ 8. For PCR amplification of the Grin 1 gene, the primers $5^{\prime}$-ATGTCAAGCCCACAATGAGT- $3^{\prime}$ and $5^{\prime}$-CCTGCTCCACGTCTACCTAA-3' were added to $50 \mathrm{ng}$ genomic DNA, and the gene was amplified using Taq DNA polymerase (Fermentas Life Sciences Canada, Burlington $\mathrm{ON}$ ). The 450 base pair (bp) product was then digested with the restriction endonuclease $M l s \mathrm{I}$ (Fermentas) and separated on a $1.5 \%$ agarose gel. Wild type fragments resisted digestion; heterozygous $+/ \mathrm{D} 481 \mathrm{~N}$ fragments resulted in three bands of 450,290 , and $160 \mathrm{bp}$, while homozygous D481N/D481N animals generated 290 and $160 \mathrm{bp}$ fragments.

\section{Electrophysiology}

Mice were decapitated under halothane anesthesia, in accordance with institutional guidelines, and the head was submerged in partially frozen artificial cerebrospinal fluid (ACSF). The contents of this ACSF used for subsequent slice preparation, storage, and some electrophysiological studies contained (in mM): $124 \mathrm{NaCl}, 26 \mathrm{NaHCO}_{3}, 10$ Glucose, 3.3 $\mathrm{KCl}, 1 \mathrm{NaHPO}_{4}, 2 \mathrm{CaCl}_{2}, 2 \mathrm{MgCl}_{2}$. Transverse slices from isolated hippocampi were cut on a Stoelting tissue chopper at $400 \mu \mathrm{m}$ and stored in a tissue chamber aerated with $95 \%$ $\mathrm{O}_{2}, 5 \% \mathrm{CO}_{2}$ at room temperature $\left(21-23^{\circ} \mathrm{C}\right)$. Slices were stored for a minimum of $1.5 \mathrm{~h}$ before experimentation. Individual slices were then transferred to a submerged superfusion chamber and secured with platinum wire. Slices were superfused at a rate of $3-4 \mathrm{ml} / \mathrm{min}$ for most experiments and at a slightly faster rate $(5 \mathrm{ml} / \mathrm{min})$ for the LTD and depotentiation studies using the glutamate uptake inhibitor TBOA (Figures 1a, b, g, and 5g). A bipolar stimulating electrode (FHC, Bowdoinham ME, USA), coupled to a physiological stimulator (Grass S88K) was placed in CA1 stratum radiatum. Field potential electrodes were pulled from $1.5 \mathrm{~mm}$ OD thin wall borosilicate glass (2$5 \mathrm{M} \Omega, \mathrm{FHC})$ and advanced just below the slice surface of CA1 stratum radiatum. In some experiments (Figures $5 \mathrm{e}$ and $\mathrm{f}$ ), a second electrode was placed in the CA1 stratum pyramidali for simultaneous fEPSP and population action potential (popAP) recordings. An Axopatch 1D amplifier (Axon Instruments, Foster City, CA) measured evoked excitatory postsynaptic field potentials (fEPSPs) in currentclamp mode, while an Axoclamp 2B amplifier was employed to measure popAPs. Slices were superfused with ACSF at $29.0 \pm 0.5^{\circ} \mathrm{C}$ for $\approx 20-30 \mathrm{~min}$ before baseline recording began. Data acquisition and analysis employed Clampex-9 software (Axon). Recordings of baseline and post-stimulus fEPSPs were filtered at $1 \mathrm{~Hz}$ low pass and $2 \mathrm{kHz}$ high pass. Recordings of fEPSPs and popAPs during $\theta$ burst stimulation (TBS) were not low pass filtered. Only hippocampal slices showing maximum fEPSP amplitudes greater than $2 \mathrm{mV}$ were used for experiments. To establish baseline (control) fEPSP slope, stimuli were delivered one every $30 \mathrm{~s}$. LTP was evoked by high-frequency stimulation, consisting of either $100 \mathrm{~Hz}$ trains or of $\theta$ burst stimulation $(50 \mathrm{~ms}$, $100 \mathrm{~Hz}$ bursts delivered at $5 \mathrm{~Hz}$ ) as indicated. Data is expressed as the slope of the fEPSP (over 20-60\% of magnitude) $v s$ time, normalized to a $20 \mathrm{~min}$ (40 sample) baseline. For figure clarity, individual fEPSPs were binned in groups of 3 or 4 . For the LTD studies illustrated in Figure 1, the divalent ion composition of the ACSF was 1.0 $\mathrm{mM} \mathrm{MgCl}_{2}$ and $2.5 \mathrm{mM} \mathrm{CaCl}_{2}$ because we found LTD to be more robust under these divalent conditions. Slices were preincubated for approximately $1 \mathrm{~h}$ before baseline recording to ensure complete re-equilibration of the extracellular cation concentration. We measured LTP and depotentiation under these same conditions for comparison. Other studies not directly comparable to the LTD experiments (Figures 2 and 5) were performed in our standard laboratory ACSF.

\section{Behavioral Testing}

Adult C57BL/6J, Grin1mutants and wild-type littermate mice were tested for spatial learning and memory in the 
a
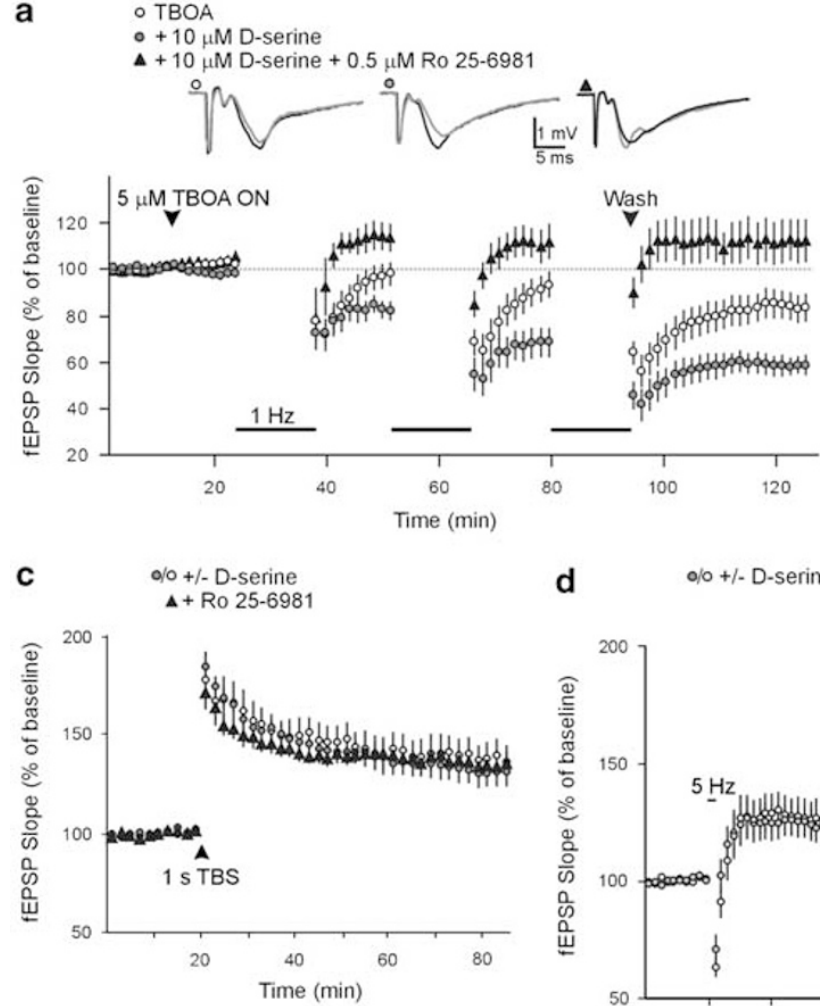

d

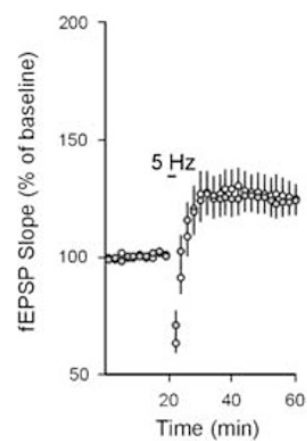

b
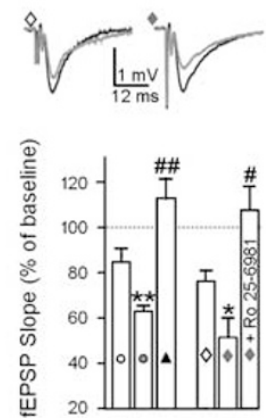

$0 \%+/$ - D-serine

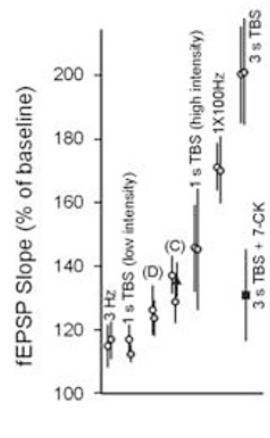

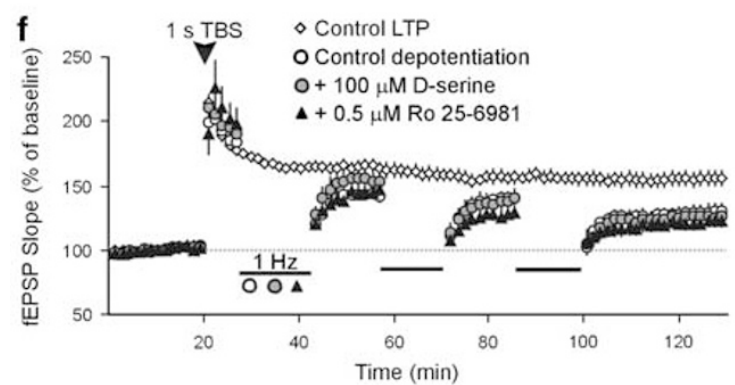

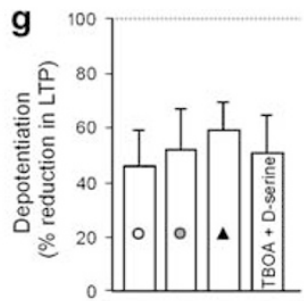

Figure I D-serine increased hippocampal LTD, but did not alter LTP or depotentiation. (a) In the presence of $5 \mu M$ TBOA, three, one Hz stimulus trains (900 pulses, fEPSPs at $40 \%$ of maximum) evoked a summating depression of the fEPSP slope (open circles). This depression was significantly increased when I $0 \mu$ M D-serine was co-applied with TBOA (closed circles), and completely inhibited by $0.5 \mu$ M of the NR2B antagonist Ro 25-698I (close triangles). Inset above: sample fEPSPs before the first I Hz train (black) and $30 \mathrm{~min}$ after the third (gray) for each condition. (b) Summary of average fEPSP amplitudes 25 30 min after the third I Hz train (TBOA vs TBOA + D-serine: $* *$ $p<0.02$; TBOA + D-serine vs TBOA + D-serine + Ro 25-698I: ${ }^{\# \# p<0.000 ~ I) . ~ R o ~ 25-698 ~ I ~}$ also inhibited the LTD induced by a single I Hz train in the presence of $30 \mu \mathrm{M}$ TBOA and $100 \mu \mathrm{M}$ D-serine. TBOA (open diamond) vs TBOA + D-serine (closed diamond): ${ }^{*} p<0.05$; TBOA + D-serine vs TBOA + D-serine + Ro 25698 I: ${ }^{*} p<0.005$. Inset above left: sample sweeps for $30 \mu M$ TBOA before and I h after I Hz stimulation. Inset above right: sample sweeps for $30 \mu \mathrm{M}$ TBOA + I00 $\mu$ M D-serine I h after I Hz stimulation. (c) In contrast, an even greater D-serine concentration ( $100 \mu \mathrm{M}$ ) did not alter the submaximal LTP induced by I s TBS (five bursts, each of six pulses at I00 Hz with fEPSP magnitude at $20 \%$ of maximum), nor was this LTP altered by Ro 25-698I. (d) D-serine did not alter the potentiation evoked by 3 min of $5 \mathrm{~Hz}$ at $40 \%$ of maximum fEPSP. (e) LTP was evoked by various stimulus protocols in the absence and presence of D-serine. Induction protocols are indicated above each group of points. LTP was measured from 50 to 60 min after induction except for 3 and $5 \mathrm{~Hz}$ experiments where it was measured 30-40 min post-stimulus. Data from (c) and (d) are also included as marked. Each point is the average of seven separate experiments, except for $100 \mathrm{~Hz}$ LTP ( $n=5$ for control and D-serine). The D-serine site antagonist 7-chlorokynurenic acid (7-CK, I0 $\mu \mathrm{M}$ ) blocked LTP induced by $3 \mathrm{~s}$ TBS. (f) D-serine (I00 $\mu \mathrm{M})$, applied immediately following I s TBS (burst were four pulses at $100 \mathrm{~Hz}$, evoked at $40 \%$ maximum fEPSP) did not alter depotentiation evoked by three, I Hz trains at 15 min intervals. (g) Summary of depotentiation experiments. Unlike LTD, depotentiation was not blocked by Ro 25-698I, nor was it altered in the presence of $0.5 \mu \mathrm{M}$ TBOA and $10 \mu \mathrm{M}$ D-serine.

Morris water maze task. Approximately equal numbers of male and female mice were used for each behavioral task. A $1.17 \mathrm{~m}$ circular pool was filled with water $\left(26 \pm 1^{\circ} \mathrm{C}\right)$ made opaque with white non-toxic paint. Distal visual cues were fixed to the room walls, approximately $1 \mathrm{~m}$ away from the pool edge, and four floor light sources of equal power provided uniform illumination to the pool and testing room. A CCD camera suspended above the pool center was used for recording, and video output was digitized by a frame grabber (HVS Image, Twickenham, Middlesex, UK) controlled by the accompanying software (HVS Water 2020). Each experimental protocol began with a single day, four-trial stationary visible platform task. Mice were released in pseudo-random order from one of four 

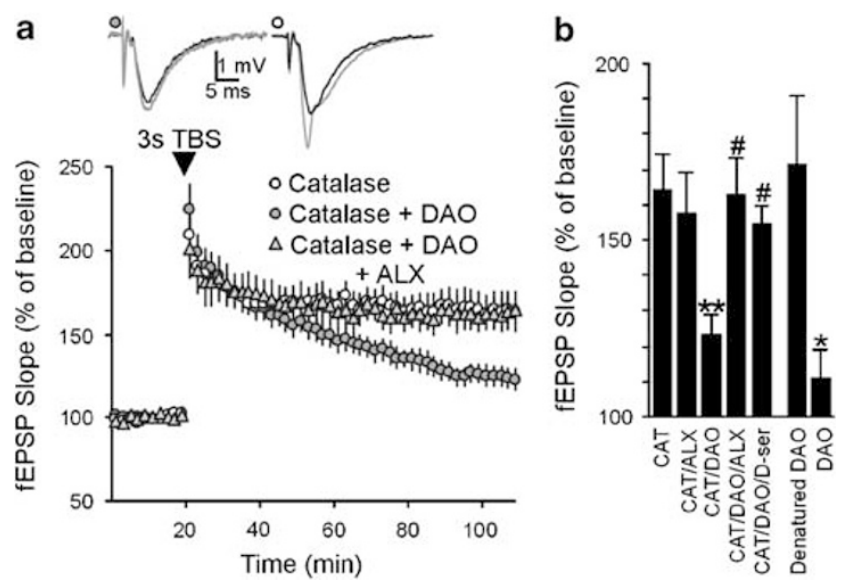

Figure 2 Endogenous D-serine is required to induce LTP. (a) LTP induced by $3 \mathrm{~s}$ TBS ( 15 bursts of six pulses at $100 \mathrm{~Hz}$ with fEPSP magnitude at $40 \%$ of maximum) at hippocampal Schaffer collateral-CAI was reduced by preincubation of the D-serine catabolic enzyme D-amino acid oxidase (DAO) and catalase (CAT, shaded circles) relative to CAT alone (open circles). The glycine transport inhibitor ALX-5407 rescued LTP in the presence of catalase and DAO (shaded triangles). Plots are of average fEPSP slope normalized to baseline \pm SE. Individual fEPSP responses obtained every $30 \mathrm{~s}$ were averaged in groups of 4 for clarity. Inset above: sample fEPSP sweeps recorded before (black) and 80 min after TBS (gray) for a slice treated with DAO and CAT (left) or CAT alone (right). (b) Summary bar graph of LTP amplitudes $80-90$ min after induction by $3 \mathrm{~s}$ TBS for each treatment studied. These data also show rescue of LTP by D-serine in DAO/catalase-treated slices, and inhibition of the DAO mediated reduction by heat denaturation (symbols: CAT + DAO vs CAT: *** $<0.004$; CAT + DAO vs CAT + DAO + ALX: * $p<0.006$, CAT + $\mathrm{DAO}+\mathrm{D}$-serine: ${ }^{*} p<0.03$; DAO vs denatured DAO: $\left.{ }^{*} p<0.04\right)$.

positions at the pool periphery. To escape, mice had to swim to a $10-\mathrm{cm}$-diameter platform that was elevated $0.5 \mathrm{~cm}$ above the water surface and demarcated with a $10 \mathrm{~cm}$ vertical pole. The edge of the platform was $30 \mathrm{~cm}$ from the pool wall in the visible and subsequent hidden platform task. The hidden platform task began 1 day later and lasted 4 or 5 days, each consisting of 4 trials with $1 \mathrm{~h}$ inter-trial intervals. The water level was adjusted so that the escape platform was submerged $\approx 1 \mathrm{~cm}$ below the surface, and mice were allowed to search for the platform for $90 \mathrm{~s}$. Mice that found the platform were left on it for $15 \mathrm{~s}$, while unsuccessful mice were assigned a $90 \mathrm{~s}$ latency and placed on the platform for $15 \mathrm{~s}$. A single probe trial was performed $24 \mathrm{~h}$ following the final set of acquisition trials in which the platform was removed from the pool. Mice were released from the point furthest from the former platform location and the swim path was recorded for $60 \mathrm{~s}$. To quantify spatial memory, we measured the time spent within an area three times the platform diameter centered at its former location. For some cohorts, the probe trial was followed by a reversal learning protocol where the hidden platform was moved to an opposite quadrant (SE to NW). Reversal learning entailed three additional days with 4 trials/day, similar to acquisition training. We also employed a delayed-matchingto-place (DMP) version of the Morris water maze (MWM) task consisting of a single day of visible platform training and 12 acquisition days where the hidden platform was moved to one of 12 predetermined locations at the beginning of each day. The edge of the platform at each position was either 25 or $40 \mathrm{~cm}$ from the wall. The methodology was similar to that described above for the stationary platform (reference memory) MWM task except that a larger 1.8 -m-diameter pool was used to increase the possible distance between platform locations. Within a training day, the platform remained in the same position for four trials with an inter-trial interval of $45 \mathrm{~min}$ between all trials.

To analyze performance in the Morris water maze, HVS Water 2020 software was used. Behavioral measures included latency to the platform, pathlength, thigmotaxis, swim speed, floating, \% time within the target area, average proximity to the target area, and the number of platform crosses. Two independent observers that were blind to treatments, genotypes, and trial classified the swim strategies using Wintrack (program by $\mathrm{Dr} \mathrm{D}$ Wolfer, www.dpwolfer.ch/wintrack). This program was used to classify search strategies into the following eight types: thigmotaxis (swimming along the wall of the pool), circling (tight circular swimming), floating (absence of swimming activity), random (swimming over the entire pool surface), scanning (swimming in straight paths predominately restricted to a central area of the pool), chaining (circular swimming at roughly the same distance from the wall as the platform), incorrect focal searching (swimming that is restricted to and repetitive within a specific area of the pool where the platform is not located), correct focal search (swimming that is restricted to and repetitive within a specific area of the pool where the platform is located), and direct swim (swimming in a straight path directly to the platform) (Wolfer and Lipp, 2000; Janus, 2004). The strategies that do not involve searching for the platform (thigmotaxis, floating, and circling) were grouped under 'not searching', the strategies that did not require allocentric navigation (random, scanning, and chaining) were grouped under 'non-spatial strategy', and the strategies that did require formation of an allocentric cognitive map (correct and incorrect focal searches, direct swim) were grouped under 'spatial strategies'.

\section{Drugs and Treatment Procedures}

Salts used for ACSF, DAO, 7-chlorokynurenic acid, ALX5407, Ro 25-6981, and $\beta$-cyclodextrin were purchased from Sigma-Aldrich Chemicals (St Louis, MO, USA). D-serine and DL-TBOA were purchased from Tocris (Ellisville, MO, USA). D-serine $(600 \mathrm{mg} / \mathrm{kg})$ was dissolved in $0.9 \% \mathrm{NaCl}$ and injected subcutaneously $20 \mathrm{~min}$ before the first trial of each day, as described previously (Lipina et al, 2005). Ro 256981, a high affinity blocker of NR2B and mixed NR2A/B NMDA receptors (Chazot et al, 2002), was dissolved in $0.9 \%$ saline with $0.3 \%$ Tween and injected subcutaneously at $5 \mathrm{mg} / \mathrm{kg} 30 \mathrm{~min}$ before the first trial of each day (Chaperon et al, 2003). No drugs were given before the probe trials.

\section{Statistical Analysis}

For electrophysiological data, one-way analysis of variance (ANOVA) with post hoc least significant difference (LSD) tests were used. Data generated in the stationary platform (reference memory) and reversal MWM task for the Grin $1^{\mathrm{D} 481 \mathrm{~N} / \mathrm{D} 481 \mathrm{~N}}$ mice were analyzed using a two-way repeated measures (RM) ANOVA with either drug treat- 
ment (saline and D-serine) or group (wild type, mutant, mutant $+D$-serine) as the between-subjects factor and days as the within-subjects factor. The DMP and the visible platform MWM task were analyzed using a two-way RM ANOVA with treatment or group as the between-subjects factor and trial as the within-subjects factor. To analyze the acquisition and reversal memory MWM task for the NR2B antagonist experiment, a three-way RM ANOVA was completed with drug treatment (vehicle, Ro 25-6981) as the between-subjects factor and days and trials as the within-subjects factors. To determine main effects within the individual days or across trials 2 and 3 on reversal days 8 and 9 (4), a two-way RM ANOVA with treatment as the between-subjects factor and trial as the within-subjects factor was used. For comparisons within individual days (Figures 3 and 6), individual trials (Figure 4), or probe trials, one way ANOVAs were used. Significant main or interaction effects were followed by a LSD post hoc test. Results were considered significant when $p<0.05$. Analysis was performed using Statistica (StatSoft Inc.).

\section{RESULTS}

\section{Endogenous D-Serine Enhanced LTD but not LTP or Depotentiation}

To examine the role of LTD in hippocampus-dependent learning, we required a method for regulating specifically this form of plasticity. The obligatory NMDA receptor coagonist D-serine augmented NMDA currents evoked by single stimuli (Mothet et al, 2000; Chen et al, 2003), indicating that the $\mathrm{D}$-serine concentration may not be sufficient to saturate the glycine site during low-frequency stimulation. Exogenous D-serine could, therefore, augment NMDA-dependent low-frequency-induced LTD. Similarly, if endogenous D-serine levels are also subsaturating during high-frequency stimulation, addition of exogenous D-serine would augment submaximal LTP.

LTD can be induced routinely at Schaeffer collateral-CA1 synapses in hippocampal slices from younger mice by lowfrequency stimulus trains alone. As they age, however, rats and mice become resistant to this protocol (Wagner and Alger, 1996). In adults, LTD can be induced by lowfrequency stimulation in the presence of glutamate transport inhibitors that facilitate stimulation of extra-synaptic NMDA-NR2B receptors (Massey et al, 2004). To measure LTD in mice that were aged matched to those used in subsequent behavioral analysis (4-6 months old), we applied $1 \mathrm{~Hz}$ stimulation during application of the glutamate transport inhibitor TBOA. In the presence of $5 \mu \mathrm{M}$ TBOA, three $1 \mathrm{~Hz}$ trains of $15 \mathrm{~min}$ duration induced a gradual synaptic depression that was significantly augmented by $10 \mu \mathrm{M}$ D-serine and blocked by $0.5 \mu \mathrm{M}$ of the NMDANR2B subunit antagonist Ro 25-6981 (25-30 min after the third train, fEPSP slopes were TBOA: $84 \pm 6 \%$ of baseline, $n=10$; TBOA + D-serine: $62 \pm 3 \%, n=9 ;$ TBOA + D-serine + Ro 25 6981: $112 \pm 9 \%, n=6$ (main effect of treatment: $\mathrm{F}_{(2,22)}=13.73, p=0.0001$; Figure $1 \mathrm{a}$ and $\left.\mathrm{b}\right)$. In contrast, an even greater D-serine concentration $(100 \mu \mathrm{M})$ did not significantly alter submaximal LTP induced by a variety of stimulus protocols designed to elicit LTP responses of varying magnitudes (including $3 \mathrm{~Hz}$ for $5 \mathrm{~min}$ with fEPSPs at $40 \%$ of maximum; $5 \mathrm{~Hz}$ for 3 min with fEPSPs at $40 \%$ of maximum; low intensity $5 \mathrm{~Hz} \theta$ burst stimulation with bursts consisting of three pulses at $100 \mathrm{~Hz}$ with fEPSPs at $20 \%$ of maximum; high intensity TBS with bursts consisting of six pulses at $100 \mathrm{~Hz}$ with fEPSPs at 20 or $40 \%$ of maximum; $3 \mathrm{~s}$ TBS with bursts of six pulses at $100 \mathrm{~Hz}, \mathrm{fEPSP}$ at $40 \%$ of maximum, $100 \mathrm{~Hz}$ for $1 \mathrm{~s}$ with fEPSP at $40 \%$ of maximum; all performed in the presence of $2.5 \mathrm{mM} \mathrm{CaCl} 2$ and $1 \mathrm{mM} \mathrm{MgCl}_{2}$ except for the last two protocols listed performed in $2 \mathrm{mM} \mathrm{CaCl}_{2}$ and $2 \mathrm{mM} \mathrm{MgCl}_{2}$; Figure $\left.1 \mathrm{c}-\mathrm{e}\right)$. LTP induced by TBS was not blocked by Ro 25-6981 (Figure 1c). Furthermore, neither exogenous D-serine nor Ro 25-6981 altered the depotentiation of pre-established LTP using the same stimulation pattern $(3 \times 900$ pulses at $1 \mathrm{~Hz}$ every $15 \mathrm{~min}$ ) employed to elicit LTD (Figure 1f and g). Similarly, addition of $5 \mu \mathrm{M}$ TBOA and $10 \mu \mathrm{M}$ D-serine did not alter depotentiation (LTP with post-tetanic TBOA and D-serine: $188 \pm 10 \%$; LTP after $3 \times 1 \mathrm{~Hz}$ stimulation: $144 \pm 11 \%$, depotentiation $=50 \pm 14 \%$; Figure $1 \mathrm{~g}$ ). Thus, the effect of exogenous D-serine was specific for Ro 256981-sensitive (NMDA-NR2B-dependent) synaptic depression; D-serine had no effect on NMDA-NR2B-independent plasticity, even when induced by the identical pattern of synaptic stimulation (depotentiation).

To show that SC-CA1 LTP was in fact dependent on endogenous D-serine, we confirmed and extended previous results by examining LTP under conditions of reduced endogenous D-serine. Extracellular D-serine was reduced by addition of DAO. Catalase (CAT) was also added in some trials because neurotoxic $\mathrm{H}_{2} \mathrm{O}_{2}$ is generated by DAOmediated catabolism of $\mathrm{D}$-serine. Slices were preincubated for $1.0-1.5 \mathrm{~h}$ in either $0.2 \mathrm{U} / \mathrm{ml} \mathrm{DAO}$ plus $260 \mathrm{U} / \mathrm{ml}$ catalase, catalase alone, $0.2 \mathrm{U}$ DAO alone, or $0.2 \mathrm{U}$ (by weight) DAO inactivated by $1-2 \mathrm{~h}$ boiling in water. In some trials using DAO plus CAT, the glycine transport blocker ALX-5407 $(1 \mu \mathrm{M})$ was co-applied $30 \mathrm{~min}$ before LTP induction; in others, $1 \mathrm{mM}$ D-serine was added $4.5 \mathrm{~min}$ earlier. Basal synaptic strength, determined by the relation between presynaptic fiber volley amplitude and postsynaptic fEPSP slope (IO), did not differ between slices preincubated in either active or denatured DAO (IO in active DAO was $103 \%$ of the IO in denatured DAO, data from 6 slices / group). The LTP induced by $3 \mathrm{~s}$ of TBS was significantly reduced by $\mathrm{DAO}$ (plus CAT) relative to CAT alone, and rescued by application of the glycine transport inhibitor ALX-5407 (LTP 85-90 min post-TBS, CAT: $164 \pm 11 \%, n=8$; CAT + DAO: $123 \pm 6 \%, n=9 ; \mathrm{CAT}+\mathrm{DAO}+\mathrm{ALX}-5407: 163 \pm 10$, $n=6$; main effect of treatment: $\mathrm{F}_{(4,26)}=3.82, p=0.014$; Figure $2 \mathrm{a}$ and $\mathrm{b})$. This deficient LTP was also rescued by application of D-serine $(157 \pm 12, n=6)$ and was not observed if DAO was first heat-inactivated (DAO alone: $110 \pm 9 \% ; n=6$; denatured DAO: $164 \pm 21, n=7$; effect of treatment: $\mathrm{F}_{(1,10)}=6.09, p=0.033$; Figure 2b).

In sum, elevating extracellular D-serine augmented LTD but was without effect on sub-maximal LTP. Furthermore, D-serine appears to be the dominant physiologic co-agonist in the hippocampus. The synaptic D-serine concentration is probably saturating at the subsynaptic NMDA-NR1 D-serine binding sites that initiate LTP and depotentiation (Liu et al, 2004) but not at the NMDA receptors that mediate LTD. This conclusion is further supported by subsequent results presented in Figures 5 and 6. 
a

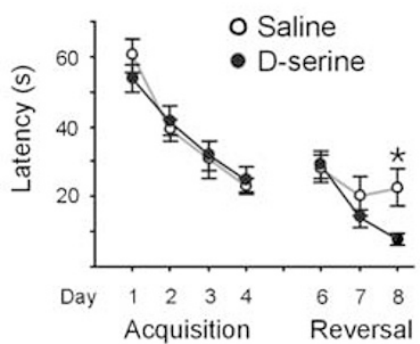

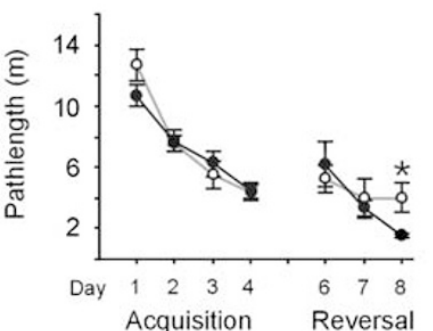

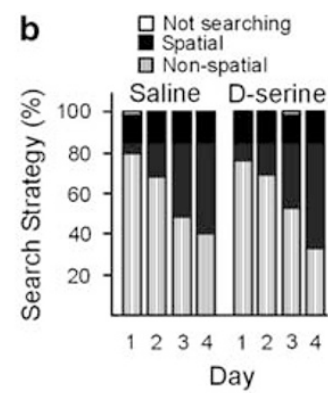

C

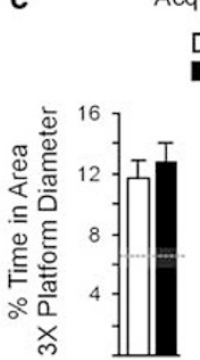

Acquisition Probe

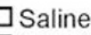

D-serine

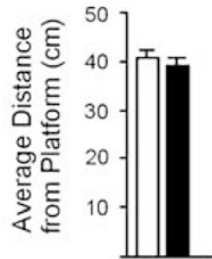

d

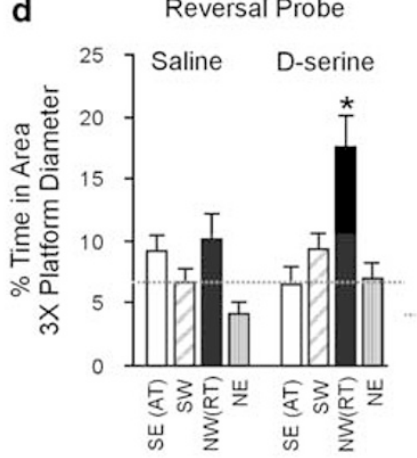

e1

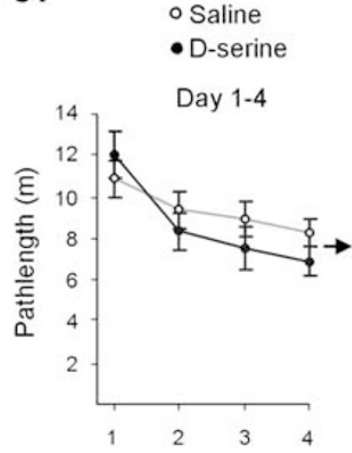

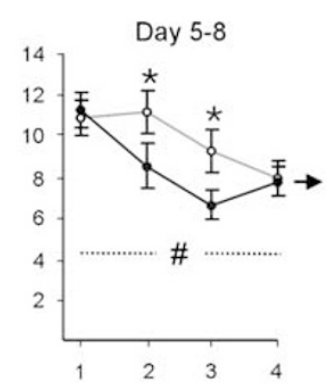

Trial Number

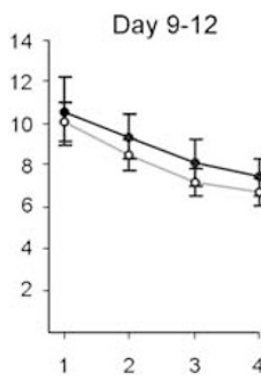

e2

Figure 3 D-serine specifically enhanced spatial reversal learning in wild type mice. (a) The effects of D-serine on spatial learning in the stationary hidden platform version of the Morris water maze. Subcutaneous injection of D-serine (600 mg/kg) did not alter the initial acquisition of a hidden platform location as measured by both latency (left panel) and pathlength (right panel). Left: latencies to reach a hidden platform over a 4 day, 4 trials/day acquisition training period did not differ between D-serine-treated (closed circles) and saline-treated wild-type mice (open circles). In contrast, when the platform was moved to the opposite quadrant (reversal), D-serine-injected mice showed reduced latencies to find the hidden platform on the third day $(* p<0.04)$ Right: similarly, the swim pathlengths from release point to platform were not altered by D-serine during acquisition training, but were significantly reduced on the third day of the reversal training $(* p<0.03)$. (b) The search strategies used over the 4 training days did not differ between saline-treated and D-serine-treated wildtype mice. Each bar shows the proportion of swims relative to the daily total ( $\mathrm{N}$ mice $\times 4$ trials/day) that were classified as not searching (floating, circling, and thigmotaxis, white area), Spatial searching (focal searches and direct swims, black area), or non-spatial searching (random, scanning, and chaining, vertical stripes). (c) The acquisition probe trial revealed that D-serine did not alter memory for the acquisition platform location. Left: the \% of time spent in an area defined by three times the platform diameter (centered on its former location) did not differ significantly between mice injected with saline and mice injected with D-serine. The dashed line is the 'chance level', corresponding to the ratio of the $3 \times$ diameter platform area to the total pool area (or 6.6\%). Right: the average distance from the AT did not differ in the acquisition probe. (d) D-serine improved memory for the reversal platform location. In the reversal probe trial, mice injected with D-serine spent significantly more time in the area three times the platform diameter, centered around the reversal target (NW-RT), than did saline-treated controls $(* P<0.03)$. (e) Preinjection with D-serine increased the rate of acquisition of a novel platform location in the DMP version of the Morris water maze. (el) The average pathlengths for each of the four daily trials over days I-4, 5-8, and 9-12 are shown for saline-injected mice (open circles) and mice injected with $600 \mathrm{mg} / \mathrm{kg}$ D-serine (closed circles) before the first trial of each day. Pathlengths were significantly reduced during days $5-8$ $\left({ }^{\#} p<0.04\right.$ is the main effect across trials 2-4). (e2) Sample swim paths from day 6, trial 2, are shown at right for a saline-injected mouse (top) and a D-serineinjected mouse (bottom).

\section{D-Serine Injection Improved Spatial Reversal Learning, but not Initial Acquisition, in Wild-Type Mice}

In light of these effects on hippocampal synaptic plasticity, we examined if exogenous D-serine altered hippocampus- dependent memory. To this end, we employed our colony of Grin1 $1^{\mathrm{D} 481 \mathrm{~N} / \mathrm{D} 481 \mathrm{~N}}$ mice (Kew et al, 2000). The Grin1 mice have been backcrossed to the C57BL6/J strain for 11 generations, so wild-type Grin $1^{+/+}$are genetically comparable to those C57BL6/J mice used for electrophysiology in Figures 1 and 2. 
a

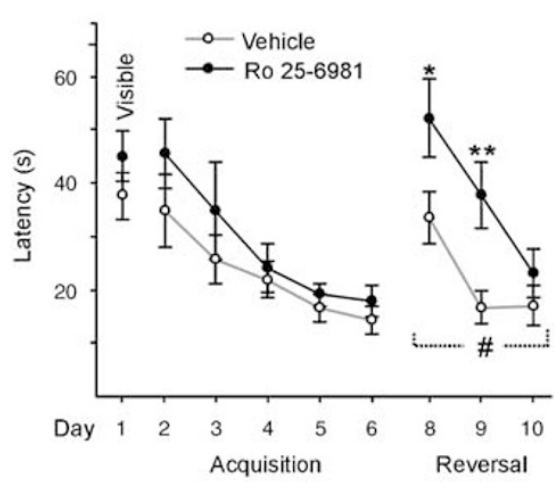

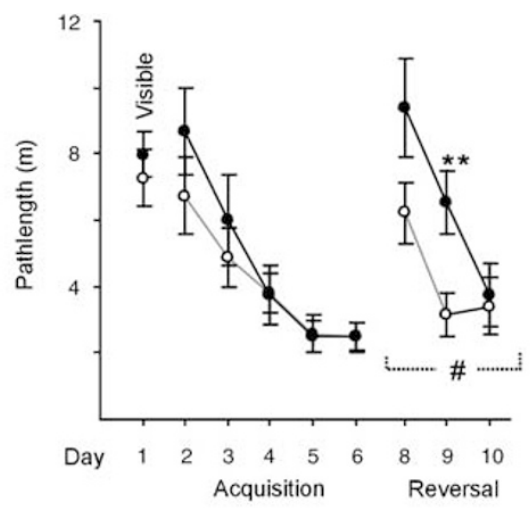

b

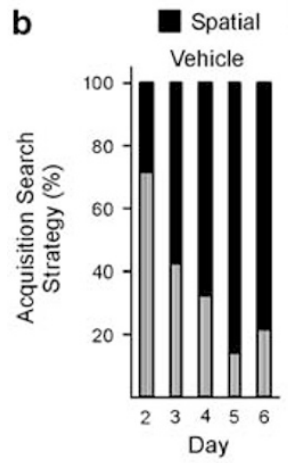

$\square$ Non-spatial Ro $25-6981$

C
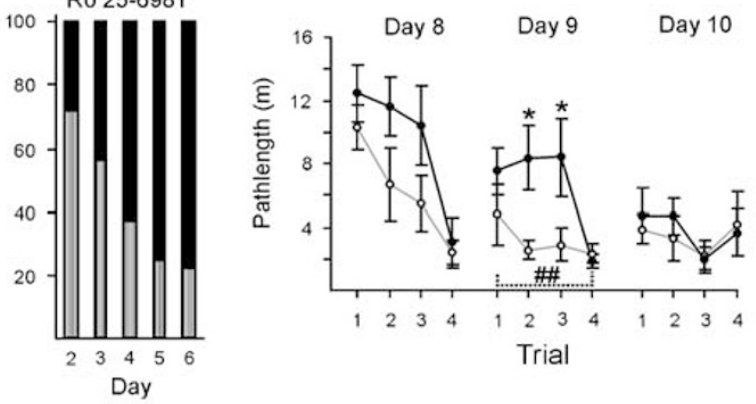

e
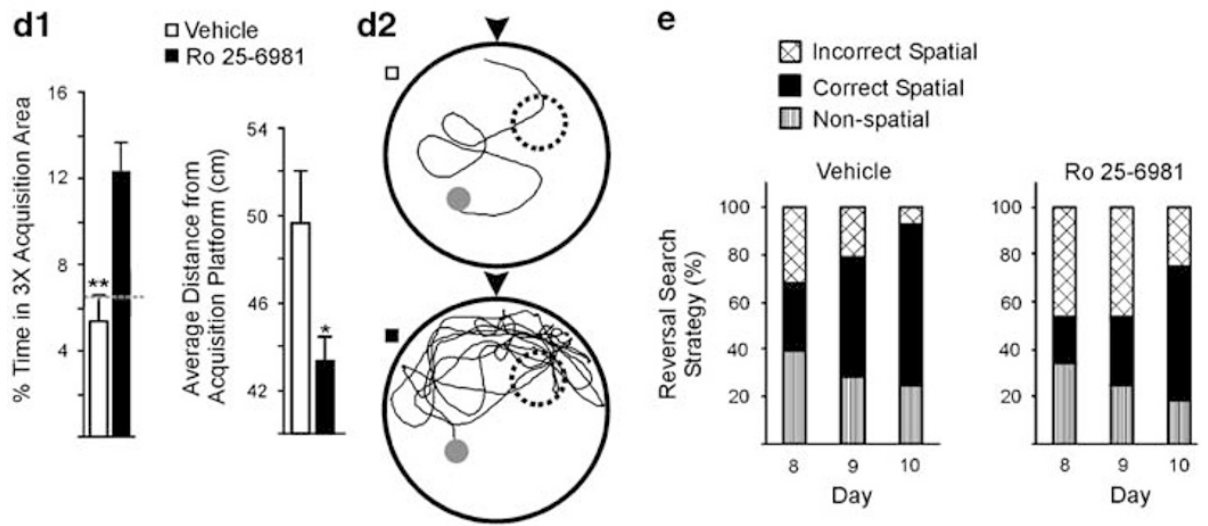

Figure 4 The NR2B antagonist Ro 25-698 I disrupts reversal learning and enhances perseveration in the Morris water maze. (a) The latency to find a platform (left panel) and pathlength (right panel) for wild type mice preinjected with vehicle (control, open circles) or $5 \mathrm{mg} / \mathrm{kg}$ Ro $25-698 \mathrm{I}$ (closed circles). Neither the latency nor pathlength to find a visible platform was significantly different between treatment groups (day I, average latency for four trials). The latency to find a submerged hidden platform (acquisition) decreased for both groups over the 5 days of training (days 2-6, 4 trials/day), but neither latencies nor pathlengths were significantly different between treatment groups overall or on any day. When the hidden platform was moved to an opposite quadrant (reversal, days 8-10), mice preinjected with Ro 25-698I showed significantly longer average escape latencies ( ${ }^{*} p<0.005$ is the main effect of drug over days, ${ }^{*} p<0.05$, ** $p<0.0$ I is main effect within days). (b) The search strategies employed by the treatment groups during acquisition training. (c) the average pathlengths to the new (reversal) platform location is plotted for each trial $(I-4)$ on each reversal training day $(\# \#$ p $<0.01$ for main effect by RM ANOVA; * $p<0.05$, post hoc LSD test). ( $\mathrm{dl}$ ) Mice treated with Ro 25-698I showed perseveration for the AT during reversal trials 2 and 3 on days 8 and 9. Left panel: the average time spent in the $3 \times$ area of the former (acquisition) location for trials 2 and 3 on days 8 and 9. Mice injected with Ro 25-698I spent significantly more time in the $3 \times$ diameter area of the old acquisition location (**p 0.0002$)$. Dashed line marks the chance time $(6.6 \%)$. Right panel: average distance from the old acquisition location was significantly shorter during the platform search in Ro 25-698I-treated mice (*⿻ $<0.04)$. (d2) Sample swim paths from trial 2, day 9, demonstrating the tendency of Ro 25-698 I-injected mice to swim in the old acquisition platform location (demarcated with dashed circle) before locating the reversal platform (gray disk). (e) Search strategies during the reversal trials. The total fraction of spatial and non-spatial swims (area with vertical stripes vs black area plus hatched area) did not differ, but Ro 25-698I-treated mice showed a greater propensity for focal searches in an incorrect acquisition platform area during reversal days.

We found no differences in basal synaptic transmission or LTP in hippocampal slices from C57BL/6J mice and Grin $1^{+/+}$ mice (LTP at $60 \mathrm{~min}$ post-tetanus, C57BL6/J: $179 \pm 8 \%$ of baseline, $n=8$; Grin $\left.1^{+/+}: 179 \pm 11 \%, n=9\right)$. In contrast, the mutant littermates (Grin $1^{\mathrm{D} 481 \mathrm{~N} / \mathrm{D} 481 \mathrm{~N}}$ ) express an NR1 subunit with 4-5-fold lower D-serine affinity (Kew et al,
2000). The Grin 1 mutant line, therefore, provides a positive control for our subsequent experiments. Furthermore, we used these mutants to support our conclusions regarding the specific enhancement of LTD by exogenous D-serine.

We first measured spatial learning in wild-type $\left(\mathrm{Grin} 1^{+/+}\right)$mice using the reference memory version of 

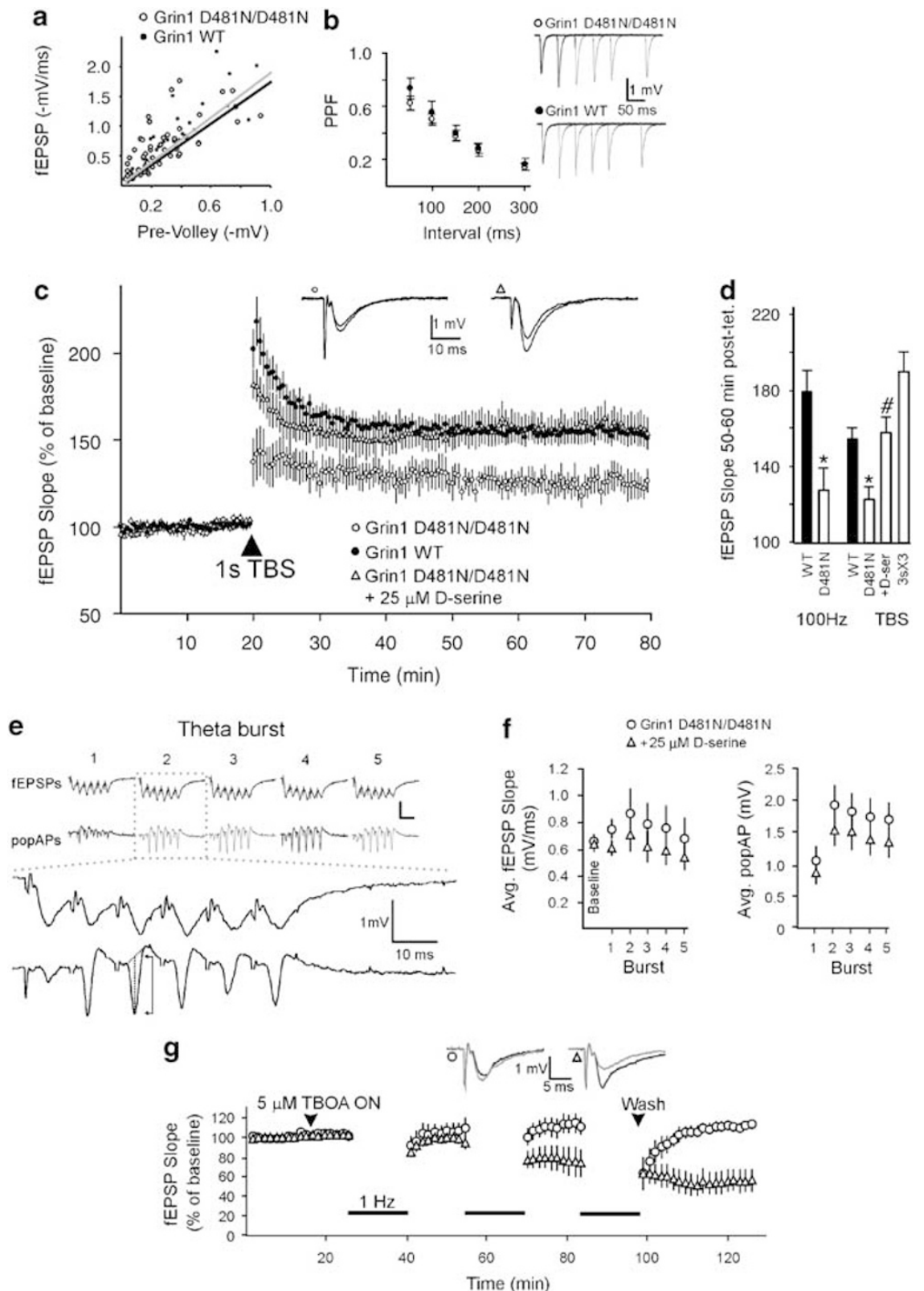

Figure 5 Exogenous D-serine rescued deficient LTP in hippocampal slices from Grin I mutant (D48IN/D48IN) mice. (a) Plot of presynaptic fiber volley amplitude against fEPSP slope for mutant (Grin I mutants, open circles) and wild type (closed circles) revealed no difference in basal synaptic strength. (b) A plot of PPF ((fEPSP2 slope/fEPSPI slope)-I) vs inter-stimulus interval revealed no difference between mutant (open circles) and wild type mice (closed circles). Inset to the right, sample fEPSPs in response to paired pulses of 50, 100, 150, 200, and $300 \mathrm{~ms}$. (c) Hippocampal slices from Grin I mutant mice exhibited diminished LTP induced by I s TBS (five bursts of six pulses at $100 \mathrm{~Hz}$ with fEPSP magnitude at $40 \%$ of maximum, open circles) relative to slices from wild type mice (closed circles). This deficient LTP was rescued by addition of exogenous D-serine $(25 \mu \mathrm{M}$, open triangles). Inset above: sample sweeps recorded $60 \mathrm{~min}$ after LTP induction in slices from Grin I mutant mice in the absence and presence of $25 \mu M$ D-serine. (d) Summary of experiments from (c). Graph also shows that slices from Grin I mutant mice displayed robust, long-lasting LTP in response to more intense stimulation (3s TBS repeated three times at 5 min intervals, labeled as $3 s \times 3$ ). Wild type vs mutant: ${ }^{*} p<0.02$; mut vs mut $+D$-serine: ${ }^{*} p<0.0 I$ ). (e and $f$ D-serine did not alter the neuronal depolarization evoked by TBS in slices from Grin I mutant mice. (e) Upper 2 traces: typical sample sweeps of simultaneously recorded fEPSP trains and popAP trains during the five $100 \mathrm{~Hz} \theta$ bursts. Note that the intervals between bursts have been omitted. Lower two sweeps: the second burst on an expanded time scale showing the method used to quantify popAP amplitude (arrows). ( $f$ ) Average intraburst fEPSP slopes (left panel) and popAP amplitudes (right panel) from Grin I mutant slices during TBS. The average intraburst fEPSP slope in the presence of D-serine (open triangles) was not significantly different from the average fEPSPs recorded in drug-free slices (open circles). Similarly, D-serine treatment had no effect on average intraburst popAP amplitude. (g) LTD could not be elicited by 3, I Hz stimulus trains in slices from Grin I mutant mice in the absence of exogenous D-serine (open circles). Inset above: sample sweeps from drug-free slices (open circle) and in the presence of D-serine (open triangles).

the Morris water maze, a test that depends on intact hippocampal function (Morris et al, 1986). Subcutaneous injection of $\mathrm{D}$-serine $(600 \mathrm{mg} / \mathrm{kg}) 20 \mathrm{~min}$ before the first of four daily trials did not augment the acquisition of a hidden platform location over a 4-day 'acquisition' training period as indicated by both the latency to find the platform (Figure 3a, left panel) and the pathlength (Figure 3a, right panel; average of 23 saline-injected and 19 D-serine-injected 
mice). Moreover, D-serine did not alter the navigational search strategy employed by wild type mice (Figure $3 \mathrm{~b}$ ). Spatial memory, as measured $24 \mathrm{~h}$ later (day 5) during a $60 \mathrm{~s}$ probe trial by the fractional time spent within an area three times the platform diameter centered over the former location $(3 \times$ diameter area $)$ was also not significantly different from saline-injected controls (Figure 3c, left panel, $p=\mathrm{NS}$ ). Furthermore, a second measure of target memory, the average distance from the target, did not differ (Figure 3c, right panel). D-serine had no significant effects on swim speed (Control: $17.9 \pm 0.4 \mathrm{~cm} / \mathrm{s}$; D-serine-injected: $18.3 \pm 0.4 \mathrm{~cm} / \mathrm{s}$ ) or on the propensity for the non-searching behaviors of floating and thigmotaxis $(p=\mathrm{NS})$. Both experimental groups, however, clearly learned the specific target platform location as evidenced by a significant preference for the $3 \times$ target location compared to the averaged analogous non-target locations (WT + saline: $\mathrm{F}_{(1,44)}=6.26, \quad p=0.016 ; \quad \mathrm{WT}+\mathrm{D}$-serine: $\quad \mathrm{F}_{(1,36)}=12.87$, $p=0.001)$.

We then sought to find a behavioral correlate to the specific alterations in LTD observed in vitro, reasoning that synaptic depression may contribute to the extinction or reversal of previously formed memories. Indeed, in contrast to acquisition of the first target, D-serine markedly enhanced the rate at which these mice learned the position of a new hidden target in a subsequent reversal learning task (Figure 3a, right side of each panel) as revealed by both significantly reduced latency and pathlength on the third day of training (effect of treatment: latency: $\mathrm{F}_{(1,21)}=4.89$, $p=0.038$; pathlength: $\mathrm{F}_{(1,21)}=6.23, p=0.021, n=12$ salinetreated, and $n=11 \mathrm{D}$-serine-treated mice). Furthermore, the memory for this new reversal target position was substantially improved. Compared to saline-treated mice, D-serineinjected mice spent significantly more time in the $3 \times$ platform diameter area (RT) during a $60 \mathrm{~s}$ probe trial $24 \mathrm{~h}$ following the third reversal training day (effect of treatment: $\mathrm{F}_{(1,21)}=5.69, p=0.027$; Figure $\left.3 \mathrm{~d}\right)$. The $\%$ time in RT was significantly greater in both groups compared to the averaged analogous area of the two non-targeted platforms (WT + saline: $\quad \mathrm{F}_{(1,22)}=4.37, \quad p=0.048 ; \quad \mathrm{WT}+\mathrm{D}$-serine: $\left.\mathrm{F}_{(1,20)}=14.04, p=0.0013\right)$. When comparing the time spent in RT to that in the former acquisition target (AT), salinetreated mice did not show a preference $\left(\mathrm{F}_{(1,22)}=0.13\right.$, $p=0.772)$, indicating that their learning was not specific for
RT over AT, whereas D-serine-injected mice showed a significant preference for RT over AT $\left(\mathrm{F}_{(1,20)}=16.08\right.$, $p=0.0007$; Figure 3d).

We next examined the effects of $D$-serine during a more rigorous reversal task, a DMP version of the Morris water maze, where the location of the hidden platform was changed daily to one of 12 preassigned positions (Figure 3e). Mice were given 4 trials/day and the pathlength of each trial was averaged in three blocks (days 1-4, 5-8, 9-12) (Nakazawa et al, 2003). Over the first 4 days of training, the trial-to-trial pathlengths were significantly reduced for both saline-treated mice $(n=16)$ and D-serinetreated mice $(n=13)$ (main effect of trials on days $1-4$ : $\left.\mathrm{F}_{(3,81)}=7.15, \quad p=0.00025\right)$. The $\mathrm{D}$-serine-injected group, however, did not reach significance compared to salineinjected controls on the non-random trials 2-4 (main effect of treatment for pathlength: $\left.\mathrm{F}_{(1,27)}=3.86, p=0.060\right)$. Over the next 4 days (5-8), a clear difference in pathlength was observed, with D-serine-injected mice showing a significantly greater decrease over the non-random trials 2-4 (main effect of treatment for pathlength: $F_{(1,27)}=5.18$, $p=0.031$, Figures $3 \mathrm{e} 1$ and $\mathrm{e} 2)$. D-serine injection had no significant effect on swim speed, floating, or thigmotaxis $(p=\mathrm{NS})$. With further training (days 9-12), saline-injected mice demonstrated similar pathlengths to the D-serine group.

\section{An NR2B-Antagonist Disrupts Spatial Reversal Learning and Promotes Perseveration}

In the present study, hippocampal LTD in adult mice was blocked by Ro 25-6981 (Figure 1a), a highly specific antagonist for the NR1-NR2B subtype of the NMDA receptor (Figure 1a). We examined the effects of systemic injection of this drug on spatial acquisition and reversal learning in the MWM task. Preinjection of Ro 25-6981 had no significant effect on either latency or pathlength to a visible platform on day 1 , or on the acquisition of a hidden platform location over 5 training days with 4 trials/day (main effect of treatment on acquisition latency: $\mathrm{F}_{(1,15)}=1.61, \quad p=0.224 ; \quad$ on pathlength: $\mathrm{F}_{(1,15)}=2.06$, $p=0.171 ; n=9$ vehicle-treated, and $n=8$ Ro 25-6981treated mice; Figure 4a). There was no change in the search strategy employed (spatial vs non-spatial) over the course of

\footnotetext{
Figure 6 Deficient spatial learning and memory in Grin I mutant mice was rescued by injection of D-serine (600 mg/kg). (a) Pathlengths during hidden platform searches for saline-injected wild type Grin I mice (open circles) and Grin I mutant mice injected with either saline (open triangles) or D-serine (closed triangles). Saline-injected Grin I mutant mice demonstrated poor acquisition of platform location during training, as indicated by a significantly longer pathlength on day 4 compared to wild-type littermates ( $\left.{ }^{*} p<0.006\right)$. This deficit was significantly reduced by injection of $\mathrm{D}$-serine $\left({ }^{\#} p<0.05\right)$. (b) The search strategies used over the 4 training days for saline-treated and D-serine-treated mice. Not searching (floating, circling, and thigmotaxis, purple), non-spatial searching (random, scanning, and chaining, green) or spatial searching (focal searches and direct swims, orange). Non-spatial strategies predominant for both saline- and D-serine-injected groups on the first two days, but are gradually replaced by spatial strategies. D-serine increased the proportion of mutant mice using spatial strategies. (c) D-serine improved memory for the platform location during the probe trial. Time spent in an area three times the platform diameter was significantly lower in saline-injected mutant mice compared to both wild type mice $(* p<0.02)$ and Grin I mutants that were injected with D-serine during training ( $\left.{ }^{*} p<0.0 \mathrm{I}\right)$. The dashed line is the chance level (6.6\%). (d) The average proximity to the target was also significantly reduced in Grin I mutants relative to wild type mice $(* p<0.005)$ and D-serine-treated mutants $\left({ }^{\#} p<0.00 \mathrm{I}\right)$. (e) Upper panels: typical swim paths during the probe trial for a saline-injected wild type mouse (left), a mutant mouse injected with saline (middle) and a mutant injected with D-serine (right). The gray disk in the lower right quadrant demarcates the $3 \times$ diameter area surrounding the former platform location. Lower panels: the spatial probability map for all animals in each group during the probe trial. Each map has a spatial resolution of approximately $5.8 \mathrm{~cm}$ (each pixel maps a pool area $5.8 \times 5.8 \mathrm{~cm}$ ). The bright green color includes the chance probability level. The highest probability (orange-red) for wild type and D-serine-treated mutants lies over the former platform location (gray disc, top row). The equivalent area for the untreated mutants is at chance (green). A second area of high probability overlies the release point (NW periphery) in all three maps.
} 
acquisition training (Figure $4 \mathrm{~b}$ ). Unlike acquisition training, Ro 25-6981-treated mice demonstrated significant deficits in acquisition memory as revealed by no preference for the target over the mean analogous non-target areas $\left(\mathrm{F}_{(1,14)}=0.04, p=0.844\right)$. In contrast, vehicle-treated mice showed a highly significant preference for the target $\left(\mathrm{F}_{(1,14)}=17.91, p=0.0008\right.$; data not shown $)$.

When the platform location was switched to the opposite quadrant, mice injected with Ro 25-6981 showed a clear deficiency in initial performance during reversal trials relative to vehicle-injected controls (main effect of drug treatment over three reversal days: latency: $\mathrm{F}_{(1,15)}=12.21$, $p=0.0033$; pathlength: $F_{(1,15)}=11.06, p=0.0046$; Figure $4 a$, reversal trials). This deficiency was significant within days on both the first (day 8) and second (day 9) reversal days (main effect of treatment for day 8 latency: $\mathrm{F}_{(1,15)}=4.75$, $p=0.0457$; day 9 latency: $\mathrm{F}_{(1,15)}=10.19, p=0.006$; day 9 pathlength: $\mathrm{F}_{(1,15)}=9.20, p=0.0084$; Figure $4 \mathrm{a}$ and $\mathrm{c}$ ). Detailed analysis of swim paths on these days revealed that trials 2 and 3 on day 9 were the most deficient trials for both
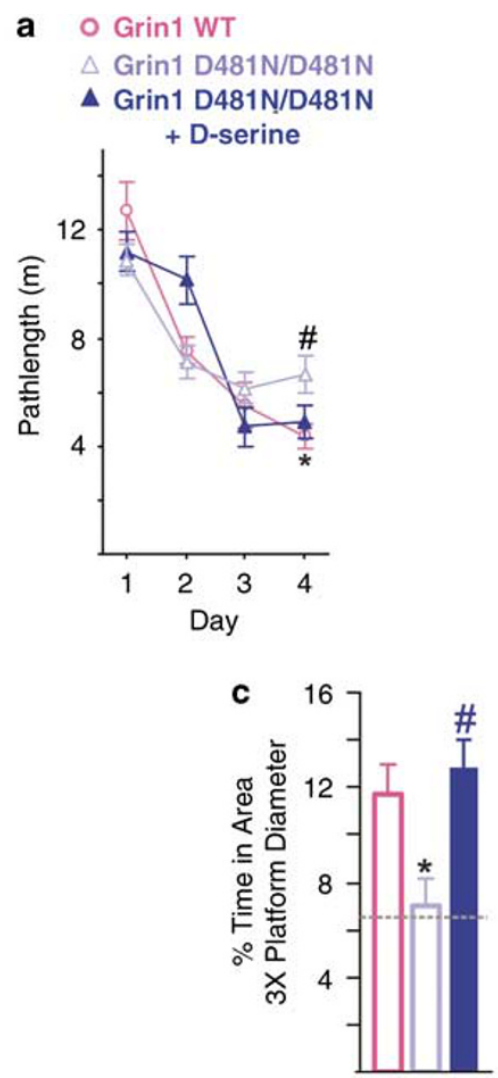

b

$$
\begin{aligned}
& \square \text { Not searching } \\
& \square \text { Spatial } \\
& \square \text { Non-spatial }
\end{aligned}
$$
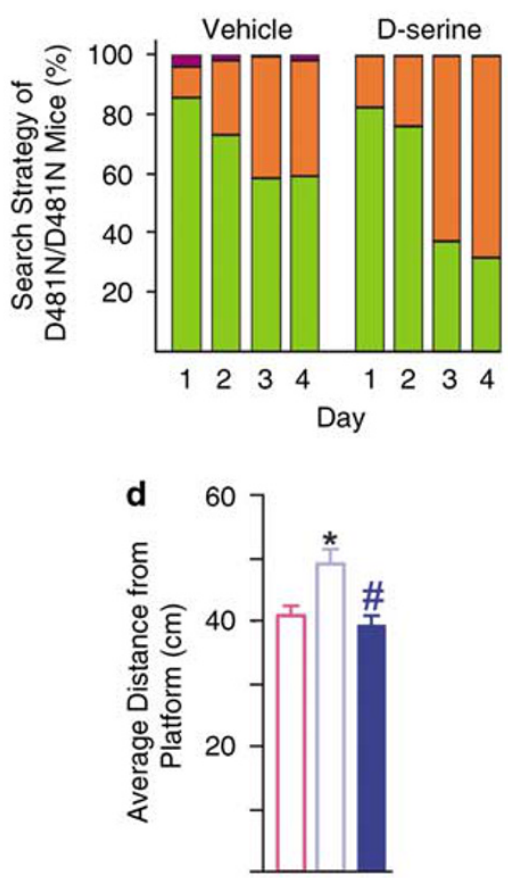
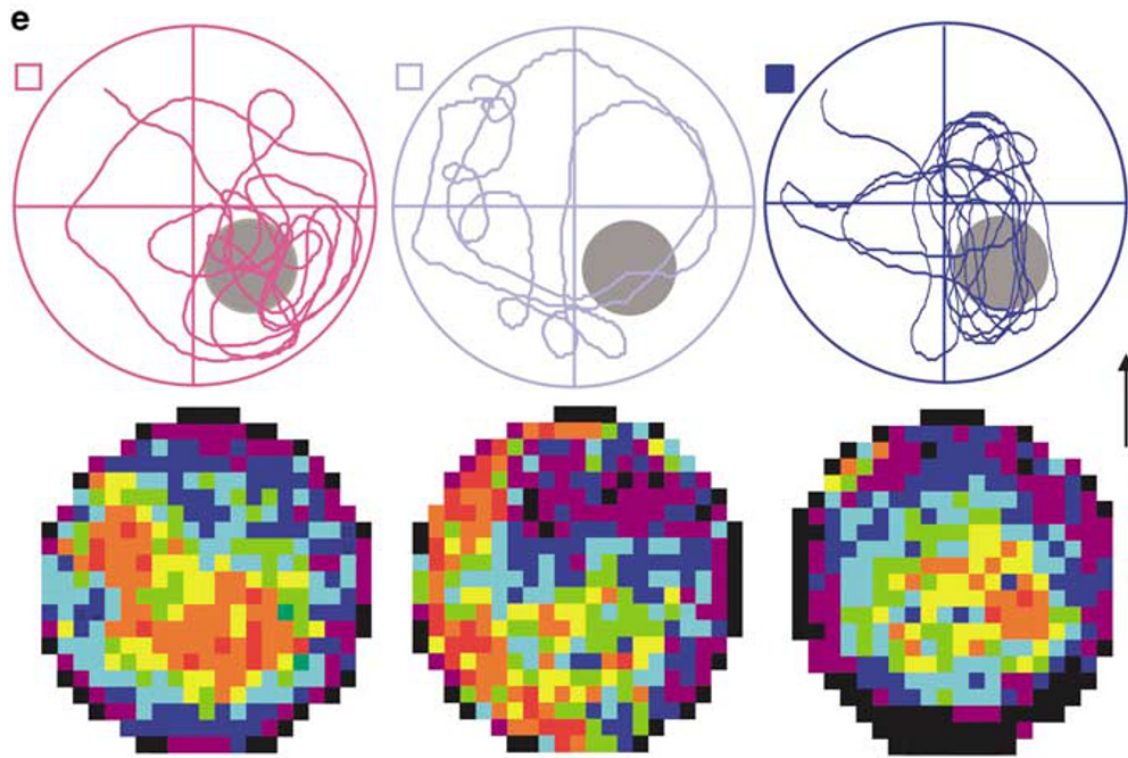
latency and pathlength (effect of treatment for latency: day 9, trial 2: $\mathrm{F}_{(1,15)}=8.79, p=0.0097$; trial 3: $\mathrm{F}_{(1,15)}=5.18$, $p=0.038$; pathlength: day 9, trial $2: \mathrm{F}_{(1,15)}=8.20$, $p=0.0118$; trial 3: $\mathrm{F}_{(1,15)}=4.67, p=0.0474$; Figure $\left.4 \mathrm{c}\right)$.

The Ro 25-6981-injected mice showed significant perseveration for the original (acquisition) platform location on trials 2 and 3 of days 8 and 9. That is, Ro 25-6981-treated mice spent significantly more time in the $3 \times$ diameter area of the acquisition platform location than did vehicleinjected controls (main effect of treatment: $F_{(1,15)}=26.09$, $p=0.00016$; Figure $4 \mathrm{~d} 1$, left), had a shorter average distance

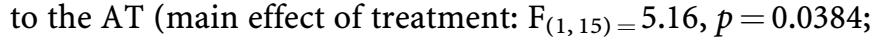
Figure $4 \mathrm{~d} 1$, right), had a reduced latency to the first AT crossing (vehicle: $45.56 \pm 8.90 \mathrm{~s}$; Ro 25-6981: $21.00 \pm 5.40 \mathrm{~s}$; main effect of treatment: $\left.F_{(1,15)}=5.22, p=0.0373\right)$, and a great number of $3 \times$ diameter AT crossings (vehicle: 1.42 \pm 0.35; Ro 25-6981: 4.84 \pm 0.73; main effect of treatment: $\left.\mathrm{F}_{(1,15)}=19.20, p=0.00054\right)$. This perseveration was also indicated by the prevalence of focal but incorrect searches relative to vehicle-treated mice (Figure 4e).

Finally, a reversal probe trial revealed a significant memory impairment in Ro 25-6981-treated mice compared to vehicle-treated mice, as indicated by reduced time in the $3 \times$ diameter reversal platform area (vehicle: $14.88 \pm 1.14 \%$; Ro 25-6981: 9.41 \pm 1.99\%; effect of treatment: $\mathrm{F}_{(1,14)}=5.67$, $p=0.0321)$, increased average distance from the reversal platform (Vehicle: $41.88 \pm 1.17 \mathrm{~cm}$; Ro 25-6981: $48.50 \pm$ $2.40 \mathrm{~cm}$; effect of treatment: $\left.\mathrm{F}_{(1,14)}=6.16, p=0.0264\right)$, and by reduced number of crossings (vehicle: $6.38 \pm 0.32$; Ro 25 -

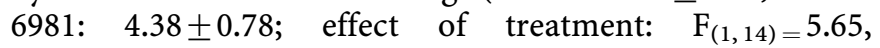
$p=0.0325)$. Also, Ro 25-6881-treated mice showed no preference in \% time spent within the reversal target area compared to either the averaged unbiased non-target areas $\left(\mathrm{F}_{(1,14)}=1.50, p=0.242\right)$ or the AT $\left(\mathrm{F}_{(1,14)}=0.31\right.$, $p=0.584)$. In contrast, vehicle-treated mice demonstrated a significant preference for the reversal target over both the averaged unbiased analogous targets $\left(\mathrm{F}_{(1,14)}=6.81\right.$, $p=0.021)$ and the AT $\left(\mathrm{F}_{(1,14)}=4.92, p=0.0435\right.$; data not shown). While Ro 25-6981 had significant effects on learning and memory, preinjection did not alter swim speed, floating, or thigmotaxis on visible, acquisition, or reversal trials $(p=\mathrm{NS})$. In sum, a drug that blocked LTD also interfered with learning and led to a perseveration behavior.

\section{D-serine Rescued LTP and Spatial Learning in Grin $1^{\text {D481N/D481N }}$ Mutant Mice}

To support further the hypothesis that the lack of effect of D-serine on TBS-evoked LTP and spatial acquisition was due to NR1 saturation (Figures $1 c, 2 a$ and $b$ ), and to determine whether our D-serine treatment protocols can enhance deficient LTP and learning, we repeated the electrophysiological and behavior tests in Grin $1^{\mathrm{D} 481 \mathrm{~N} / \mathrm{D} 481 \mathrm{~N}}$ mutants. Synaptic strength, as indicated by the prevolley amplitude to fEPSP slope relation, was not altered by the Grin1 mutation (Figure 5a), indicating that basal AMPA-mediated neurotransmission was unchanged. Similarly, paired-pulse facilitation (PPF), a presynaptic form of short-term potentiation that may regulate LTP by controlling the level of postsynaptic depolarization, was unaltered (Figure $5 \mathrm{~b}, n=9$ slices). Compared to wild-type littermates, Grin $1^{\text {D481N/D481N }}$ mutant mice expressed a major LTP deficit in response to $1 \mathrm{~s}$ of TBS that was rescued by addition of exogenous D-serine (at $1 \mathrm{~h}$ post-TBS, wild-type LTP: $154 \pm 6 \%$, $n=9$; Grin $1^{\mathrm{D} 481 \mathrm{~N} / \mathrm{D} 481 \mathrm{~N}}$ LTP: $123 \pm 7 \%, n=7$; LTP in Grin $1^{\mathrm{D} 481 \mathrm{~N} / \mathrm{D} 481 \mathrm{~N}}+25 \mu \mathrm{M}$ D-serine: $158 \pm 8 \%, n=9$; effect of group: $F_{(2,22)}=6.40, p=0.006$; Figure $5 c$ and $\left.d\right)$. This LTP deficit and rescue by exogenous $D$-serine may be explained by the lower NR1 D-serine affinity conferred by the D481N mutation. In contrast to wild-type mice, exogenous synaptic D-serine may be subsaturating at CA3-CA1 synapses due to the expression of the low-affinity mutant NR1, leading to aberrantly reduced NMDA receptor activation that is restored by exogenous $\mathrm{D}$-serine.

Activation of NMDA receptors also depend on depolarization from AMPA-mediated EPSPs and action potentials, so it is possible that D-serine rescued LTP by enhancing neuronal depolarization. To examine this possibility, we measured simultaneous fEPSPs and population action potentials (popAPs) during TBS (Figure 5e). Application of D-serine $(25 \mu \mathrm{M})$ did not significantly alter the average intraburst fEPSP slope or the average intraburst popAP recorded during individual theta frequency bursts (average of seven TBS responses from seven drug-free slices and nine responses from nine D-serine-treated slices; Figure 5f). Consequently, the rescue of LTP in Grin1 mutants by D-serine is most likely due to enhanced NMDA receptor activation independent of membrane potential.

Finally, we showed that the Grin 1 mutation also reduced LTD. Slices from these mice were resistant to LTD induction using the stimulation protocol employed previously in wild-type mice $(110 \pm 5 \%$ of baseline, $n=6)$ unless the exogenous $\mathrm{D}$-serine $(25 \mu \mathrm{M})$ was added $(58 \pm 11 \%$ of baseline, $n=5, p<0.005$, Figure $5 \mathrm{~g}$ ).

Grin $1^{\mathrm{D} 481 \mathrm{~N} / \mathrm{D} 481 \mathrm{~N}}$ mutant mice also demonstrated a significant deficit in memory for the hidden platform location compared to wild type littermates (Figure 6a; average of 23 wild type, 24 saline-injected mutant mice, and $16 \mathrm{D}$-serine injected mutant mice). Subcutaneous injection of $600 \mathrm{mg} / \mathrm{kg} \mathrm{D}$-serine improved acquisition relative to saline-treated mutants by the fourth training day (group $\times$ days interaction for pathlength: $\mathrm{F}_{(6,180)}=3.83, p=0.0013$; effect of group for pathlength on training day 4: $\mathrm{F}_{(2,60)}=4.46, p=0.0156$; main effect of group for average distance from target: $\mathrm{F}_{(2,60)}=9.22, p=0.00032$; group $\times$ days interaction for average distance; $F_{(6,180)}=2.83$, $p=0.012$; effect of group for average distance on day 4 : $\left.\mathrm{F}_{(2,60)}=9.50, p=0.0003\right)$. Post hoc LSD tests revealed a significant effect between wild type and mutant mice for pathlength (day $4: p=0.0055$ ), average distance from target (day 4: $p=0.00025$ ), and between saline-treated and D-serine-treated mutants for pathlength (day 4: $p=0.050$ ), and average distance from the target (day $4: p=0.001$ ).

Injection of $\mathrm{D}$-serine also altered the prevailing swim strategy (Figure 6b). During the early training days, Grin 1 mutants predominantly employed non-spatial search strategies (chaining, random swimming, and scanning). With training, such search strategies diminished and spatial or focal strategies emerged. D-serine increased the propensity for spatial searching, the increased efficiency of which could account for the observed improvement in performance.

Saline-treated Grin1 mutants performed very poorly in the subsequent probe trial relative to wild-type and 
D-serine-treated littermates, as measured by time spent in the $3 \times$ diameter area of the former target (effect of group: $\mathrm{F}_{(2,59)}=5.17, p=0.0085$; Figure $\left.6 \mathrm{c}\right)$, by the average distance to the platform (effect of group: $\mathrm{F}_{(2,59)}=7.79, p=0.001$; Figure $6 \mathrm{~d}$ ), by the latency to the first crossing (wild type: $11.22 \pm 1.77$; mutants: $23.22 \pm 6.02$; D-serine-injected mutants: $9.78 \pm 2.12$; effect of group $\left.\mathrm{F}_{(2,59)}=3.25, p=0.0456\right)$, and by number of crossings over the $3 \times$ diameter area (wild type: $6.04 \pm 0.50$ passes, $n=23$; mutants: $3.13 \pm 0.47$ passes $n=23$; D-serine-injected mutants: $6.36 \pm 0.83, \bar{n}=16$; effect of group: $\left.\mathrm{F}_{(2,59)}=9.82, p=0.0002\right)$. Post hoc analysis revealed significant differences between wild type and mutants in time in the $3 \times$ diameter area $(p=0.011)$, average distance from platform $(p=0.0026)$, latency to first crossing $(p=0.035)$, and number of crossings over the $3 \times$ diameter area $(p=0.0004)$, and between saline-treated and $\mathrm{D}$-serine-treated mutants in time spent $(p=0.0062)$, average distance $(p=0.0008)$, latency $(p=0.0325)$, and number of crossings $(p=0.00035)$. There were no significant differences in these parameters between wild type and $\mathrm{D}$-serine-treated mutants, indicating that $\mathrm{D}$-serine rescued the spatial learning and memory deficit in the Grin1 mutants. These effects are demonstrated by the spatial probability map derived from the swim paths recorded during the probe trial (Figure 6e, lower panels). Both wildtype mice and D-serine-treated mutants showed significant preferences for the target over the averaged analogous nontarget locations (wild type: $\mathrm{F}_{(1,44)}=6.26, p=0.016$; mutant $+\mathrm{D}$-serine: $\left.\mathrm{F}_{(1,30)}=4.39, p=0.045\right)$, while the saline-treated mutants showed no preference $\left(\mathrm{F}_{(1,44)}=2.18, p=0.153\right)$.

To verify that the Grin1 mutation and D-serine did not affect motor co-ordination, vision, or motivation, groups were trained for four trials in a visible platform MWM task. Even though this test was run in a larger $(1.8 \mathrm{~m})$ pool to exacerbate any differences, neither latency nor pathlength differed between wild types, saline-treated wild types, and saline-treated mutants (main effect of group for latency:

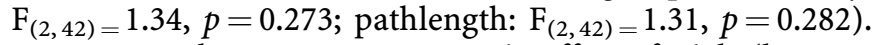
In contrast, there was a strong main effect of trials (latency: $\mathrm{F}_{(3,126)}=37.23, p=2.7 \times 10^{-17}$; pathlength: $\mathrm{F}_{(3,126)}=28.31$, $\left.p=4.6 \times 10^{-14}\right)$, indicating that learning in the groups occurred across trials. Average swimming speed did not differ between mutant and wild type mice as measured on the day 4 of hidden platform training (wild type: $16.9 \pm 0.5 \mathrm{~cm} / \mathrm{s}$; mutants: $15.5 \pm 0.7 \mathrm{~cm} / \mathrm{s}$ ). Finally, we used a 'probe trial' following a 12 day delayed-matching to place training session (as in Figure 3c) to demonstrate that neither wild type nor mutant mice had an inherent bias for quadrant location (main effect of \% time spent in each quadrant: $\left.\mathrm{F}_{(3,39)}=0.21, p=0.888\right)$.

In sum, these results indicate that exogenous $\mathrm{D}$-serine can rescue spatial learning, but only when endogenous $\mathrm{D}$-serine is limiting, in this case by a reduced NR1 affinity.

\section{DISCUSSION}

Exogenous D-serine selectively enhanced NMDA-NR2B receptor-dependent LTD at hippocampal CA3-CA1 synapses in vitro, and improved reversal learning in hippocampus-dependent behavioral tasks. Conversely, the NR2B-selective antagonist Ro 25-6981 disrupted both hippocampal LTD and reversal learning with a concomitant increase in perseveration. These results point to an important role for NMDA-NR2B receptor-mediated plasticity in hippocampus-dependent reversal learning, and suggest that $\mathrm{D}$-serine may improve cognitive flexibility by enhancing this process.

\section{Specific Regulation of NMDA-NR2B-Dependent LTD by Extracellular D-Serine}

The most parsimonious explanation for the specific enhancement of NMDA-NR2B-dependent LTD by exogenous $\mathrm{D}$-serine is that normal endogenous $\mathrm{D}$-serine levels are subsaturating in the proximity of NR2B-expressing receptors, but are near saturation at those NMDA receptors mediating the induction of LTP and depotentiation. $\mathrm{D}$-serine is clearly the dominant physiological co-agonist for activation of NMDA receptors linked to LTP, as evidenced by the inhibitory effect of the catabolic enzyme D-amino acid oxidase and rescue by D-serine (Yang et al, 2003). Furthermore, exogenous D-serine rescued LTP and LTD in Grin1 mutants expressing a lower NMDA-NR1 D-serine affinity, indicating that exogenous D-serine application substantially increased the intra-synaptic D-serine concentration. That this treatment had no effect on submaximal LTP in wild-type mice indicates that $\mathrm{D}$-serine is normally not the limiting factor for NMDA receptor activation during tetanic stimulation (Billups and Attwell, 2003).

Alternatively, D-serine is most likely subsaturating around NMDA-NR2B receptors that mediate LTD, so that exogenous D-serine can increase receptor activity. Receptors expressing NR2B subunits have a co-agonist affinity that is actually higher than those expressing only NR2A (Priestley et al, 1995), so any difference in the degree of saturation must be determined by extracellular concentration gradients. Astrocytic processes containing D-serine are directly opposed to the synapses and so are in close proximity to subsynaptic NMDA receptors (Schell et al, 1997). In the mature hippocampus, however, NR2B-containing receptors are thought to be primarily extra-synaptic (Clark and CullCandy, 2002) and so may be exposed to lower D-serine concentrations emanating from a relatively distal source. Alternatively, differential saturation could reflect a dynamic coupling of $\mathrm{D}$-serine release to the frequency of synaptic activation, with more D-serine released by LTP-inducing high-frequency stimulation. Aside from synthesizing and storing D-serine (Schell et al, 1995, 1997; Mothet et al, 2000; Wolosker et al, 1999), perisynaptic astroglial processes express a variety of neurotransmitter receptors and ion channels, and so are well positioned to respond in a graded manner to transmitters and ions (Vesce et al, 1999; Scemes, 2000; Somjen, 2002). However, depotentiation was not altered by exogenous $\mathrm{D}$-serine, indicating that synaptic D-serine levels are sufficient to saturate these NMDA-NR2B antagonist-insensitive receptors at low frequencies $(1 \mathrm{~Hz})$.

\section{The Role of NR2B-Dependent Synaptic Plasticity in Hippocampus-Dependent Reversal Learning}

The precise neurocellular mechanisms underlying hippocampus-dependent spatial learning are still debated, but activation of hippocampal NMDA receptors and the 
induction of multiple forms of NMDA-dependent synaptic plasticity appear necessary (Martin et al, 2000; Lynch, 2004). Our results indicate that the NMDA-NR2B subtype of NMDA receptor mediates a form of hippocampal synaptic depression that may contribute to spatial reversal learning and oppose behavioral perseveration. D-serine augmented NR2B-dependent hippocampal LTD and improved reversal learning in both a reversal version of a reference memory task, and in a hippocampus-dependent version of the delayed-matching-to place task (Steele and Morris, 1999). Conversely, blockade of NMDA-NR2B receptors inhibited both LTD and reversal learning, and significantly increased the time mice spent within the previous acquisition target. This behavior is referred to as perseveration, and significantly, is also observed after partial damage to the hippocampus or transection of the fibria-fornix (Whishaw and Tomie, 1997). Thus, while systemic injection of D-serine and Ro 25-6981 will, respectively, augment and suppress NMDA-NR2B receptor activity throughout the brain, it is likely that actions within the hippocampus account for the deficit in reversal learning and increased perseveration.

Evidence for a unique role of NMDA-NR2B receptors in synaptic plasticity and learning has been somewhat contradictory, possibly due to species-dependent differences and changes in receptor subtypes during development. Hippocampal overexpression of the NR2B subunit was shown to enhance learning in the MWM task in adult mice (Tang et al, 1999). Consistent with these transgenic studies, we observed that pharmacologic downregulation of NR2B receptor function disrupted spatial memory in wild type mice. In contrast, NR2B antagonists had no effect on spatial memory in rats (Guscott et al, 2003; Higgins et al, 2003), suggesting that encoding of spatial memories may be more dependent on other NMDA receptor isoforms in mice.

There is also considerable ambiguity regarding the differential contributions of NR2A- and NR2B-containing receptors to hippocampal LTP and LTD. The idea that NR2A and NR2B subtypes have strictly delineated roles in the induction of LTP and LTD respectively is very likely an oversimplification. NR2B receptors have been shown to participate in LTP induction at young mouse CA3-CA1 synapses (Berberich et al, 2005, 2007), as well as in other brain regions (Rodrigues et al, 2001; Weitlauf et al, 2005; Zhao et al, 2005). The NR2B-antagonist Ro 25-6981 blocked LTD in adult rats (Liu et al, 2004; Massey et al, 2004) but, conversely, did not block hippocampal LTD in very young rats in vitro (Bartlett et al, 2007; Morishita et al, 2006). Curiously, however, this drug inhibited LTD in young rats in vivo (Fox et al, 2006). A putative NMDA-NR2A-specific antagonist also blocked LTD (Fox et al, 2006) but has also been shown to inhibit NR1-NR2B receptors (Weitlauf et al, 2005; Frizelle et al, 2006). It should be emphasized that the subcellular distribution of NR2A and NR2B receptors changes during maturation of the hippocampus (Dumas, 2005), so direct comparisons between young rats or mice and the adult mice employed in our study are not possible. Furthermore, the different LTD induction protocols employed may engage different signaling pathways that could account for some of these discrepancies. The LTD induction method employed here (see Massey et al, 2004) induces a form of LTD that requires Ro 25-6981-sensitive NR2B receptors. Likewise, the $\theta$ burst protocol that closely mimics the endogenous hippocampal firing pattern (O'Keefe, 1993) induces LTP that is NR2B receptor-independent. The strongest evidence that an NR2B-dependent LTD is involved in reversal learning in vivo is the opposing effects of D-serine and the NMDA-NR2B antagonist on both reversal learning and in vitro LTD. Disruption of reversal learning was concomitant with perseveration. In light of previous results showing that the same NMDA-NR2B antagonist promotes perseveration in a serial reaction task (Higgins et al, 2003), we suggest that a major function of NR2Bmediated LTD is to augment behavioral flexibility, independent of the specific cognitive requirements of the task.

How specifically could LTD and NMDA-NR2B receptors facilitate behavioral flexibility? By weakening certain synapses in response to changing environmental conditions, LTD could enhance the signal-to-noise, dynamic range, and plasticity of hippocampal circuits. Indeed, the propensity for LTD has been shown to change during exploration and learning. In rats, the threshold for LTD was lowered by exposure to a simple but novel environment, and when the positions of salient cues within that environment were changed (Manahan-Vaughan and Braunewell, 1999; Kemp and Manahan-Vaughan, 2004). Changing the location of a hidden platform may be analogous, requiring a refinement or reconfiguration of the previously formed spatial map. Similarly, calcineurin knockout mice show both diminished LTD and poor performance in the delayed-matching-to-sample task (Zeng et al, 2001), while environmental enrichment, the most studied form of cognitive enhancement, increases the propensity for LTP, LTD, and depotentiation/dedepression (Duffy et al, 2001; Abraham et al, 2006; Artola et al, 2006). Modulation of LTD threshold has also been associated with cognitive dysfunction; for example, chronic stress reduces the induction threshold for LTD and leads to cognitive impairments ( $\mathrm{Xu}$ et al, 1997; Yang et al, 2005). However, our results, and those cited, indicate that LTD is not necessarily detrimental to explicit learning. Rather, whether LTD promotes or inhibits learning depends on the context of induction. Specific enhancement of LTD by D-serine would increase the dynamic range of hippocampal synapses, and so long as LTD and LTP induction occur in appropriate contexts, learning may be improved.

\section{D-Serine in Psychiatric Disease}

Recent evidence points to NMDA-receptor hypofunction mediated by low $\mathrm{D}$-serine as a specific causative factor in some behavioral endotypes of schizophrenia (Mohn et al, 1999; Goff and Coyle, 2001; Chumakov et al, 2002). Treatments that can augment the synaptic concentrations of D-serine or glycine are, therefore, possible therapies (Javitt, 2004). Indeed, rodents treated with NMDA receptor antagonist show behavioral endotypes of schizophrenia that can be partially ameliorated by D-serine (Andersen and Pouzet, 2004; Lipina et al, 2005). The role of D-serine as a cognitive enhancer in the normal brain is not as well documented. Here we show that D-serine does not improve acquisition of spatial tasks in wild-type mice, but allows acquired information to be utilized more effectively under changing conditions. These findings underscore the potential of $\mathrm{D}$-serine in the treatment of a range of behavioral 
anomalies characterized by perseveration of aberrant ideation and behaviors.

\section{ACKNOWLEDGEMENTS}

SD is a Daniel Maltz National Alliance for Research on Schizophrenia and Depression (NARSAD) Young Investigator. VL was supported by a Natural Sciences and Engineering Research Council (NSERC, Canada) studentship. JCR holds a Canada Research Chair (CRC). This work was supported by the Canadian Institutes of Health Research (CIHR). We thank Dushyandi Rajendran and Marijana Kanisek for technical assistance and Dr Franco Taverna, Dr Stephen J Clapcote, and Greer Kirshenbaum for critically reading the manuscript.

\section{DISCLOSURE/CONFLICT OF INTEREST}

The author(s) Dr Steven Duffy, Dr John C Roder, and Ms Viviane Labrie declare that, except for income received from our primary employer, no financial support or compensation has been received from any individual or corporate entity over the past three years for research or professional service and there are no personal financial holdings that could be perceived as constituting a potential conflict of interest.

\section{REFERENCES}

Abraham WC, Mason-Parker SE, Irvine GI, Logan B, Gill AI (2006). Induction and activity-dependent reversal of persistent LTP and LTD in lateral perforant path synapses in vivo. Neurobiol Leaning Mem 86: 82-90.

Andersen JD, Pouzet B (2004). Spatial memory deficits induced by perinatal treatment of rats with PCP and reversal effect of D-serine. Neuropsychopharmacol 29: 1080-1090.

Artola A, von Frijtag J, Fermont PCJ, Gispen WH, Schrama LH, Kamal A et al (2006). Long-lasting modulation of the induction of LTD and LTP in hippocampal CA1 by behavioral stress and environmental enrichment. Eur J Neurosci 23: 261-272.

Bartlett TE, Bannister NJ, Collett VJ, Dargan SL, Massey PV, Bortolotto ZA et al (2007). Differential roles of NR2A and NR2B-containing NMDA receptors in LTP and LTD in the CA1 region of two-week-old rat hippocampus. Neuropharmacology 52: $60-70$.

Berberich S, Jensen V, Hvalby O, Seeburg PH, Kohr G (2007). The role of NMDAR subtypes and charge transfer during hippocampal LTP inudction. Neuropharmacology 52: 77-86.

Berberich S, Punnakkal P, Jensen V, Pawlak V, Seeburg PH, Hvalby O et al (2005). Lack of NMDA receptor subtype selectivity for hippocampal long-term potentiation. J Neurosci 25: 6907-6910.

Billups D, Attwell D (2003). Active release of glycine or D-serine saturates the glycine site of NMDA receptors at the cerebellar mossy fibre to granule cell synapse. Eur J Neurosci 18: 2975-2980.

Chaperon F, Muller W, Auberson YP, Trickleback MD, Neijt HC (2003). Substitution for PCP, disruption of prepulse inhibition and hyperactivity induced by $\mathrm{N}$-methyl-D-aspartate receptor antagonists: preferential involvement of the NR2B rather than NR2A subunit. Behav Pharmacol 14: 477-487.

Chazot LP, Lawrence S, Thompson CL (2002). Studies on the subtype selectivity of CP-101,606: evidence for two classes of NR2B-selective NMDA receptor antagonists. Neuropharmacol 42: $319-324$
Chen L, Muhlhauser M, Yang CR (2003). Glycine tranporter-1 blockade potentiates NMDA-mediated responses in rat prefrontal cortical neurons in vitro and in vivo. J Neurophysiol 89: 691-703.

Chumakov I, Blumenfeld M, Guerassimenko O, Cavarec L, Palicio $\mathrm{M}$, Abderrahim $\mathrm{H}$ et al (2002). Genetic and physiological data implicating the new human gene G72 and the gene for D-amino acid oxidase in schizophrenia. Proc Natl Acad Sci USA 99: 13675-13680.

Clark BA, Cull-Candy SG (2002). Activity-dependent recruitment of NMDA receptor activation at an AMPA receptor-only synapse. J Neurosci 22: 4428-4436.

Clements JD, Westbrook GL (2001). Activation kinetics reveal the number of glutamate and glycine binding sites on the N-MethylD-Aspartate receptor. Neuron 7: 605-613.

Cull-Candy S, Brickely S, Farrant M (2001). NMDA receptor subunits: diversity, development and disease. Curr Op Neurobiol 11: $327-335$

Dudek SM, Bear MF (1992). Homosynaptic long-term depression in area CA1 of hippocampus and effects of N-methyl-D-aspartate receptor blockade. Proc Natl Acad Sci USA 89: 4363-4367.

Duffy S, Craddock KJ, Abel T, Nguyen PV (2001). Environmental enrichment modifies the PKA-dependence of hippocampal LTP and improves hippocampus-dependent memory. Learn Mem 8: 26-34.

Dumas TC (2005). Developmental regulation of cognitive abilities: modified composition of a molecular switch turns on associative learning. Prog Neurobiol 76: 189-211.

Fox CJ, Russell KI, Wang YT, Christie BR (2006). Contribution of NR2A and NR2B subunits to bidirectional synaptic plasticity in the hippocampus in vivo. Hippocampus 16: 907-915.

Frizelle PA, Chen PE, Wyllie DJ (2006). Equilibrium constants for (R)-[(S)-1-(4-bromo-phenyl)-ethylamino]-(2,3-dioxo-1,2,3,4-tetrahydroquinoxalin-5-yl)- methyl]-phosphonic acid (NVPAAM077) acting at recombinant NR1/NR2A and NR1/NR2B N-methyl-D-aspartate receptors: implications for studies of synaptic transmission. Mol Pharmacol 70: 1022-1032.

Goff DC, Coyle JT (2001). The emerging role of glutamate in the pathophysiology and treatment of schizophrenia. Am J Psychiatry 158: 1367-1377.

Guscott MR, Clarke HF, Murray F, Grimwood S, Bristow LJ, Hutson PH (2003). The effect of $( \pm)-C P-101,606$, an NMDA receptor NR2B subunit selective antagonist, in the Morris watermaze. Eur J Pharmacol 476: 193-199.

Hayashi F, Takahashi K, Nishikawa T (1997). Uptake of D and L-serine in C6 glioma cells. Neurosci Lett 239: 850-858.

Higgins GA, Ballard TM, Huwyler J, Kemp JA, Gill R (2003). Evaluation of the NR2B-selective NMDA receptor antagonist Ro 93-1908 on rodent behavior: evidence for an involvement of NR2B NMDA receptors in response inhibition. Neuropharmacol 44: 324-341.

Janus C (2004). Search strategies used by APP transgenic mice during navigation in the Morris water maze. Learn Mem 4: 337-346.

Javitt DC (2004). Glutamate as a therapeutic target in psychiatric disorders. Mol. Psychiatry 1: 1-14.

Johnson JW, Ascher P (1987). Glycine potentiates the NMDA response in cultured mouse brain neurons. Nature 325: 529-531.

Kemp A, Manahan-Vaughan D (2004). Hippocampal long-term depression and long-term potentiation encode different aspects of novelty acquisition. Proc Natl Acad Sci USA 101: 8192-8197.

Kemp N, Bashir ZI (2001). Long-term depression: a cascade of induction and expression mechanisms. Prog Neurobiol 64: 339-365.

Kew JNC, Koester A, Moreau J-L, Jenck F, Quagazzal A-M, Mutel V et al (2000). Functional consequences of reduction in NMDA receptor glycine affinity in mice carrying targeted point mutations in the glycine binding site. J Neurosci 20: 4037-4049. 
Lipina T, Labrie V, Wiener I, Roder J (2005). Modulators of the glycine site on NMDA receptors, D-serine and ALX 5407, display similar beneficial effects to clozapine in mouse models of schizophrenia. Psychopharmacol 179: 54-67.

Liu L, Wong TP, Pozza MF, Lingenhoehl K, Wang Y, Sheng M et al (2004). Role of NMDA receptor subtypes in governing the direction of hippocampal synaptic plasticity. Science 304: 1021-1024.

Loftis JM, Janowsky A (2003). The N-methyl-D-aspartate receptor subunits NR2B: localization, functional properties, regulation and clinical implications. Pharmacol Rev 97: 55-85.

Lynch MA (2004). Long-term potentiation and memory. Physiol Rev 84: 87-136.

Manahan-Vaughan D, Braunewell K-H (1999). Novelty acquisition is associated with induction of hippocampal long-term depression. Proc Natl Acad Sci USA 96: 8739-8744.

Martin S, Grimwood P, Morris RGM (2000). Synaptic plasticity and memory: an evaluation of the hypothesis. Annu Rev Neurosci 23: 649-711.

Massey PV, Johnson BE, Moult PR, Auberson YP, Brown MW, Molnar E et al (2004). Differential roles of NR2A and NR2Bcontaining NMDA receptors in cortical long-term potentiation and long-term depression. J Neurosci 24: 7821-7828.

Mohn AR, Gainetdinov RR, Caron MG, Koller BH (1999). Mice with reduced NMDA receptor expression display behaviors related to schizophrenia. Cell 98: 427-436.

Morris RG, Anderson E, Lynch GS, Baudry M (1986). Selective impairment of learning and blockade of long-term potentiation by an N-methyl-D-aspartate receptor antagonist, AP5. Nature 319: $774-776$.

Mothet J-P, Parent AT, Wolosker H, Brady RO, Linden DJ, Ferris CD et al (2000). D-serine is an endogenous ligand for the glycine site of the N-methyl-D- aspartate receptor. Proc Natl Acad Sci USA 97: 4926-4931.

Monyer H, Burnashev N, Laurie DJ, Sakmann B, Seeburg PH (1994). Developmental and regional expression in the rat brain and functional properties of four NMDA receptors. Neuron 12: 529-540.

Morishita W, Lu W, Smith GB, Nicoll RA, Bear MF, Malenka RC (2006). Activation of NR2B-containing NMDA receptors is not required for NMDA receptor- dependent long-term depression. Neuropharmacology 52: 71-76.

Nakazawa K, Sun LD, Quirk MC, Rondi-Reig L, Wilson MA, Tonegawa S (2003). Hippocampal CA3 NMDA receptors are crucial for memory acquisition of one-time experience. Neuron 38: 305-315.

O'Keefe J (1993). Hippocampus, theta, and spatial memory. Curr Op Neurobiol 3: 917-924.

Priestley T, Laughton P, Myers J, Le Bourdelles B, Kerby J, Whiting PJ (1995). Pharmacological properties of recombinant human Nmethyl-D-aspartate receptors comprising NR1a/NR2A and NR1a/NR2B subunit assemblies expressed in permanently transfected mouse fibroblast cells. Mol Pharmacol 48: 841-848.

Rodrigues SM, Schafe GE, LeDoux JE (2001). Intra-amygdala blockade of the NR2B subunit of the NMDA receptor disrupts the acquisition but not the expression of fear conditioning. J Neurosci 21: 6889-6896.

Scemes E (2000). Components of astrocytic intercellular calcium signaling. Mol Neurobiol 22: 167-179.
Schell MJ, Brady RO, Molliver ME, Snyder SH (1997). D-serine as a neuromodulator: regional and developmental localizations in rat brain glial resemble NMDA receptors. J Neurosci 17: 1604-1615.

Schell MJ, Molliver ME, Snyder SH (1995). D-serine, an endogenous synaptic modulator: localization to astrocytes and glutamate-stimulated release. Proc Natl Acad Sci USA 92: 3948-3952.

Somjen GG (2002). Ion regulation in the brain: implications for pathophysiology. Neuroscientist 8: 254-267.

Steele RJ, Morris RG (1999). Delay-dependent impairment of a matching to place task with chronic and intrahippocampal infusion of the NMDA- antagonist D-AP5. Hippocampus 9: 118-136.

Tang Y-P, Ahimizu E, Dube GR, Rampon C, Kerchner GA, Zhuo M et al (1999). Genetic enhancement of learning and memory in mice. Nature 401: 63-69.

Vesce S, Bezzi P, Volterra A (1999). The active role of astrocytes in synaptic transmission. Cell Mol Life Sci 56: 991-1000.

Wagner JJ, Alger BE (1996). Homosynaptic LTD and depotentiation: do they differ in name only? Hippocampus 6: 24-29.

Wake K, Yamazaki H, Hanzawa S, Konno R, Sakio H, Niwa A et al (2001). Exaggerated responses to chronic nociceptive stimuli and enhancement of $\mathrm{N}$-methyl-D-asparate receptor-mediated synaptic transmission in mutant mice lacking D-amino-acid oxidase. Neurosi Lett 297: 25-28.

Weitlauf C, Honse Y, Auberson YP, Mishina M, Lovinger DM, Winder DG (2005). Activation of NR2B-containing NMDA receptors is not obligatory for NMDA receptor-dependent long-term potentiation. J Neurosci 25: 8386-8390.

Whishaw IQ, Tomie J-A (1997). Perseveration on place reversals in spatial swimming pool tasks: further evidence for place learning in hippocampal rats. Hippocampus 7: 361-370.

Wolfer DP, Lipp H-P (2000). Dissecting the behavior of transgenic mice: is it the mutation, the genetic background, or the environment? Exp Physiol 85: 621-634.

Wolosker H, Blackshaw S, Snyder SH (1999). Serine racemase: a glial enzyme synthesizing $\mathrm{D}$-serine to regulate glutamate-Nmethyl-D-aspartate neurotransmission. Proc Natl Acad Sci USA 96: 13409-13414.

Xu L, Anwyl R, Rowan MJ (1997). Behavioral stress facilitates the induction of long-term depression in the hippocampus. Nature 387: 497-500.

Yang C-H, Huang C-C, Hsu K-S (2005). Behavioral stress enhances hippocampal CA1 long-term depression through the blockade of glutamate uptake. J Neurosci 25: 4288-4293.

Yang Y, Ge W, Chen Y, Shen W, Wu C, Poo M et al (2003). Contribution of astrocytes to hippocampal long-term potentiation through release of D-serine. Proc Natl Acad Sci USA 100: 15194-15199.

Zeng H, Chattarji S, Barbarosie M, Rondi-Reig L, Philpot BD, Miyakawa T et al (2001). Forebrain-specific calcineurin knockout selectively impairs bidirectional synaptic plasticity and working/episodic-like memory. Cell 107: 617-629.

Zhao M-G, Toyoda H, Lee Y-S, Wu L-J, Ko SW, Zhang X-H et al (2005). Roles of NMDA NR2B subtype receptor in prefrontal long-term potentiation and contextual fear memory. Neuron 47: 859-872. 